\title{
Reciclagem de óleo lubrificante ferroviário usado utilizando extração por solventes verdes assistido por ultrassom indireto
}

O objetivo deste estudo foi investigar a reciclagem do óleo lubrificante ferroviário por extração com solventes orgânicos polares assistida por uso indireto de ultrassom que fundamentou nos parâmetros de solubilidade de Hansen e nos critérios de sustentabilidade para a seleção de solventes orgânicos. Foi determinado o parâmetro de solubilidade de Hansen do óleo lubrificante ferroviário comercial com 25 solventes orgânicos. Os resultados da esfera de solubilidade do óleo, o parâmetro de solubilidade experimental e os dados teóricos de 1236 solventes, e o critério de sustentabilidade, foram utilizados para selecionar os melhores solventes extratores polares isobutanol, 1-butanol e metil etil cetona. feito um planejamento experimental de mistura Simplex-Lattice [3,3] do processo de extração do óleo recuperado em banho de ultrassom de $37 \mathrm{kHz}$ na temperatura de $30^{\circ} \mathrm{C}$ no tempo de exposição de 5 min. A mistura solvente/óleo foi submetida a dois processos de extração: uso de ultrassom indireto (banho) e agitação mecânica, como controle. Os resultados mostraram que os parâmetros de solubilidade do óleo lubrificante ferroviário comercial foram 15,8, 3,8 e 7,6 MPa0.5 para o parâmetro de dispersão, polar e ligação de hidrogênio, respectivamente. A qualidade do óleo recuperado após 0 procedimento de extração, foi avaliada pela densidade, viscosidade cinemática a $40^{\circ} \mathrm{C}$ até $100^{\circ} \mathrm{C}$ e Índice de Viscosidade. Os rendimentos de recuperação de óleo usando US foram de $64,0 \%$ $\mathrm{m} / \mathrm{m}$ (isobutanol), $89,1 \% \mathrm{~m} / \mathrm{m}$ (1-butanol) e 91,2\% m/m (MEK). Os rendimentos para agitação mecânica nas mesmas condições foram inferiores ao encontrados em US: 56,3\% m/m, 83,4\% $\mathrm{m} / \mathrm{m}$ e $89,1 \% \mathrm{~m} / \mathrm{m}$ para os solventes isobutanol, 1-butanol e MEK, respectivamente. Os óleos recuperados com os solventes isobutanol, 1-butanol e MEK apresentaram, respectivamente, Índice de Viscosidade de 73, 84 e 88 para US e de 68, 76 e 82 para AM. Portanto, o uso de ultrassom é promissor para auxiliar no processo de reciclagem de óleo lubrificante ferroviário usado.

Palavras-chave: Óleo lubrificante ferroviário usado; Parâmetro de solubilidade; Solvente; Índice de viscosidade; Ultrassom.

\section{Recycling of used railroad lubricating oil using indirect ultrasound- assisted green solvent extraction}

\begin{abstract}
The objective of this study was to investigate railway lubricating oil recycling by extraction with polar organic solvents assisted by indirect use of ultrasound, which was based on Hansen's solubility parameters and sustainability criteria for the selection of organic solvents. Hansen's solubility parameter of commercial railway lubricating oil with 25 organic solvents was determined. The results of the oil solubility sphere, the experimental solubility parameter and the theoretical data of 1236 solvents, and the sustainability criterion, were used to select the best polar extractors isobutanol, 1-butanol and methyl ethyl ketone. An experimental planning of the Simplex-Lattice mixture [3,3] of the extraction process of the oil recovered in a $37 \mathrm{kHz}$ ultra pound bath was carried out ultrasound bath was carried out at a temperature of $30^{\circ} \mathrm{C}$ in the exposure time of $5 \mathrm{~min}$. The solvent/oil mixture was subjected to two extraction processes: use of indirect ultrasound (bath)
and mechanical agitation, as a control. The results showed that the solubility parameters of the commercial railway lubricating oil were $15.8,3.8$ and $7.6 \mathrm{MPa0} .5$ for the dispersion, polar and and mechanical agitation, as a control. The results showed that the solubility parameters of the commercial railway lubricating oil were $15.8,3.8$ and $7.6 \mathrm{MPa} .5 \mathrm{for}$ the dispersion, polar and hydrogen bonding parameters, respectively. The quality of the oil recovered after the extraction procedure was evaluated by density, kinematic viscosity at $40{ }^{\circ} \mathrm{C}$ to $100{ }^{\circ} \mathrm{C}$ and Viscosity
Index. The yields of oil recovery using US were $64.0 \% \mathrm{w} / \mathrm{w}$ (isobutanol), $89.1 \% \mathrm{w} / \mathrm{w}$ (1-butanol) and $91.2 \% \mathrm{w} / \mathrm{w}$ (MEK). The yields for mechanical agitation in the same conditions were lower Index. The yields of oil recovery using US were $64.0 \% \mathrm{w} / \mathrm{w}$ (isobutanol), $89.1 \% \mathrm{w} / \mathrm{w}$ (1-butanol) and $91.2 \% \mathrm{w} / \mathrm{w}$ (MEK). The yields for mechanical agitation in the same conditions were lower
than those found in US: $56.3 \% \mathrm{w} / \mathrm{w}, 83.4 \% \mathrm{w} / \mathrm{w}$ and $89.1 \% \mathrm{w} / \mathrm{w}$ for the solvents isobutanol, 1-butanol and MEK, respectively. The oils recovered with the solvents isobutanol, 1 -butanol and MEK showed, respectively, a Viscosity Index of 73, 84 and 88 for US and 68,76 and 82 for AM. Therefore, the use of ultrasound is promising to assist in the recycling process of used railway lubricating oil.
\end{abstract}

Keywords: Used railway lubricating oil; Solubility parameter; Solvent; Viscosity index; Ultrasound.

Topic: Logística Reversa

Reviewed anonymously in the process of blind peer.
Received: 05/06/2021

Approved: 26/06/2021
Paulo André Prata Decoté (iD

Universidade Federal do Espírito Santo, Brasi http://lattes.cnpq.br/8198323176384225 http://orcid.org/0000-0002-0141-5043

paulodecote@hotmail.com

Amanda Puttin Vidoto

Universidade Federal do Espírito Santo, Brasil

http://lattes.cnpq.br/7010555107826313

http://orcid.org/0000-0002-2526-2774

amandaputtinvidoto@hotmail.com

\section{Maristela de Araujo Vicente (it)}

Universidade Federal do Espírito Santo, Brasil

http://lattes.cnpq.br/1832685910267156

http://orcid.org/0000-0002-2575-2386

maristelavicente@gmail.com

d

DOI: 10.6008/CBPC2179-6858.2021.006.0036
Maria de Fatima Pereira dos Santos (ic)

Universidade Federal do Espírito Santo, Brasil

http://lattes.cnpq.br/0376041929696875

http://orcid.org/0000-0001-6165-003X

maria.f.santos@ufes.br
Referencing this:

DECOTÉ, P. A. P.; VIDOTO, A. P.; VICENTE, M. A.; SANTOS, M. F. P.. Reciclagem de óleo lubrificante ferroviário usado utilizando extração por solventes verdes assistido por ultrassom indireto. Revista Ibero Americana de Ciências Ambientais, v.12, n.6, p.426-447, 2021. DOI: http://doi.org/10.6008/CBPC2179-6858.2021.006.0036 


\section{INTRODUÇÃO}

O óleo lubrificante é uma das frações de petróleo mais importantes usado para todos os tipos de veículos, máquinas e locomotivas. Devido a sua composição de óleo básico e aditivos, o óleo lubrificante desempenha um papel crítico para reduzir o atrito, o desgaste e garantir que as máquinas e motores sejam mais eficientes em termos de potência e economia de combustível (SPEIGHT, 2014). O consumo de óleo lubrificante acompanha as variações do desenvolvimento econômico com o estabelecimento de novas indústrias, o aumento no número de transporte de cargas e passageiros, a mecanização da agricultura e indústrias, bem como também acompanha as crises econômicas mundiais (JAFARI et al., 2015).

Aliado a esse elevado consumo de óleo lubrificante está a geração exponencial de resíduos. Com o tempo de uso, o óleo lubrificante sofre deterioração ou contaminação, perdendo suas propriedades iniciais e não servindo mais para a finalidade a qual foi elaborado, exigindo sua substituição para garantir a integridade e o bom funcionamento do motor ou equipamento (SPEIGHT et al., 2014). Esse produto, após ser retirado do motor ou equipamento recebe o nome de óleo lubrificante usado ou contaminado (OLUC) e passa a ser um resíduo perigoso por apresentar toxicidade elevada, conforme classifica a NBR 10004 (ABNT, 2004).

O OLUC constitui um grave problema de poluição, uma vez que o despejo ilegal ou disposição inadequada pode contaminar as águas subterrâneas, as águas superficiais e os solos (PINHEIRO et al., 2020). Se queimado como combustível sem um tratamento prévio para a remoção de contaminantes, poluentes tóxicos podem ser liberados para a atmosfera (HASSANAIN et al., 2017). A resolução CONAMA no 362/2005 dispõe no art. 1ํ que todo óleo lubrificante usado ou contaminado deverá ser recolhido, coletado e ter destinação final, de modo que não afete negativamente o meio ambiente e propicie a máxima recuperação dos constituintes nele contidos (CONAMA, 2005). A coleta e tratamento adequado do OLUC reduz seus impactos ambientais e preserva recursos valiosos com grande valor econômico (TSAI, 2011). A reciclagem do OLUC também pode ser promissora para produção de nanotubos de carbono e outras aplicações (ABDULLAH et al., 2020; ALAVI et al., 2020; MEDEIROS et al., 2014).

O OLUC é uma importante matéria-prima para o rerrefino, pois durante sua utilização não se degrada totalmente, podendo dele ser recuperado, o óleo base, que pode ser reaproveitado para o mesmo fim (GRICE et al., 2014). O rerrefino, que consiste em submeter os óleos lubrificantes usados a uma série de processos capazes de eliminar os contaminantes, incluindo água, partículas sólidas, compostos solúveis, produtos de oxidação e aditivos, permitindo a recuperação de suas propriedades iniciais e podendo ser devolvido ao ciclo produtivo para ser reutilizado na formulação de novos produtos (HASSANAIN et al., 2017; PINHEIRO et al., 2020).

Alguns processos de rerrefino de OLUC incluem argila acida, destilação e desasfaltamento por solvente (JAFARI et al., 2015; PINHEIRO et al., 2020; SPEIGHT et al., 2014). Tecnologias de rerrefino como o tratamento com ácido-argila que embora produz um óleo básico de alta qualidade, esse processo vem sendo descontinuado uma vez que gera um resíduo ácido altamente tóxico e de difícil descarte (HAMAD et al., 
2005). Outra técnica de rerrefino é a evaporação por película que consiste em um processo mais ecológico do que o tratamento com argila ácida, porém apresenta alguns problemas de operação como a incrustação de equipamentos (BOTAS et al., 2017).

O rerrefino com solventes polares pode ser uma alternativa interessante aos tratamentos convencionais uma vez que o solvente dissolve o óleo básico e simultaneamente promove a separação dos contaminantes, contaminantes estes que podem ser utilizados como componentes de tintas offset, classe especial de tinta gráfica, ou usadas em indústrias de asfalto (QURASHI et al., 2018; SATHISKUMAR et al., 2019). Todos esses fatores tornam a extração com solventes um método simples, econômico e sem a geração de novos resíduos (ASSUNÇÃO FILHO et al., 2010; REIS et al., 1990).

A escolha do solvente adequado é de fundamental importância no processo de extração. A remoção de impurezas promovida pelos solventes pode ser correlacionada com várias características, como a diferença nos parâmetros de solubilidade dos solventes e do óleo básico, a polaridade e a viscosidade dos solventes e temperatura (PINHEIRO et al., 2018; SPEIGHT et al., 2014; WIDODO et al., 2018). Um aumento de temperatura, por exemplo, pode aumentar a solubilidade mútua de óleo e solvente, porém também pode reduzir a capacidade de segregar os contaminantes do OLUC (REIS et al., 1990). Uma solução possível a esses problemas é a misturas de solventes individuais (solvente composto) que pode ser explorada com base na escolha apropriada de componentes e composições visando encontrar formulações com um equilíbrio favorável das propriedades dos solventes individuais (RINCON et al., 2005).

Atualmente busca-se o desenvolvimento de estratégias sustentáveis para processos de separação, promovendo o uso de solventes alternativos de fontes renováveis (JORDAN et al., 2020; MUSARURWA et al., 2020; YARA-VARON et al., 2016). A substituição de solvente em um processo deve ter como princípio manter as propriedades de extração, eficiência e características tecnológicas. O parâmetro de solubilidade de Hansen tem sido descrito como uma ferramenta para auxiliar na seleção de solventes para extração. 0 método da esfera de solubilidade de Hansen calcula o parâmetro de solubilidade usando uma avaliação de afinidade que leva em consideração as interações com vários solventes orgânicos ( SÁNCHEZ-CAMARGO et al., 2019; KATO et al., 2020; LEVIN et al., 2008).

O parâmetro de solubilidade permite compreender o fenômeno da solubilidade, predizer o melhor solvente em processos de extração para determinado soluto e, ainda, se as interações intermoleculares entre as moléculas do soluto e do solvente são da mesma ordem de grandeza (ABBOTT et al., 2015; HANSEN, 2007). Devido a essas características, os parâmetros de solubilidade são aplicados em uma variedade de fenômenos físicos, tais como adsorção, dissolução, dispersão e difusão, sendo ainda aplicados em processos que utilizam solventes para remoção de contaminantes de óleos lubrificantes usados (LEVIN et al., 2008). A primeira teoria para o parâmetro de solubilidade foi proposta por Hildebrand, apresentando algumas limitações por ter como base apenas o comportamento dos solventes apolares. Para aprimorar esse estudo, surgiu o parâmetro de solubilidade proposto por Hansen que considerou o somatório das várias forças presentes em uma molécula recebendo, portanto, contribuições relativas as forças de dispersão, interações dipolo-dipolo ou polares e as forças de ligação de hidrogênio. Dessa forma, o parâmetro de solubilidade de Hansen é 
representado pela Equação (1) (HANSEN, 2007; REIS et al., 1990; WENG, 2016).

$$
\delta_{\mathrm{T}}=\sqrt{\delta_{\mathrm{D}}^{2}+\delta_{\mathrm{P}}^{2}+\delta_{\mathrm{H}}^{2}}
$$

Em que $\delta_{\mathrm{T}}$ é o parâmetro de Hildebrand (também chamado de parâmetro total), $\delta_{\mathrm{D}}$ é o parâmetro de dispersão de Hansen, $\delta_{\mathrm{P}}$ é o parâmetro polar de Hansen e $\delta_{\mathrm{H}}$ é o parâmetro de ligação de hidrogênio de Hansen, sendo estes parâmetros tabelados por Hansen para os mais diversos solventes. O parâmetro de solubilidade pode ser determinado experimentalmente em ensaios de solubilização com diversos solventes.

Diversos autores investigaram o uso de solventes para recuperação de óleo utilizando óleo lubrificante automotivo (ELBASHIR et al., 2002; HAMAD et al., 2005; OSMAN et al., 2018; PINHEIRO et al., 2018; ZGHEIB et al., 2020). Solventes como álcoois e cetonas foram os mais eficientes para extração, uma vez que são miscíveis com o óleo base, porém floculam alguns dos aditivos e compostos carbonáceos pela aplicação de um efeito antissolvente. A capacidade de segregar o resíduo está intimamente relacionada à diferença entre a solubilidade do solvente e do poliisobutileno, um aditivo melhorador de viscosidade (REIS et al., 1988; 1990). Misturas de solventes em sistemas ternários podem reduzir o efeito de contaminação do óleo melhorando a separação da borra residual (RINCON et al., 2005; VELASCO-CALDERÓN et al., 2020). Pinheiro et al. propôs uma metodologia para seleção de solventes para recuperação de óleo lubrificante para 154 solventes e observou que 1-butanol, isobutanol e metil etil cetona são os mais sustentáveis (PINHEIRO et al., 2018). As quantidades e toxicidade dos reagentes, resíduos gerados, requisitos de energia, número de etapas do procedimento, miniaturização e automação são apenas alguns dos vários critérios considerados ao avaliar a sustentabilidade de uma metodologia analítica (PENA-PEREIRA et al., 2020).

A extração assistida por ultrassom é uma técnica eficiente e ecológica porque apresenta vantagens como tempos de extração mais curtos, consumo reduzido de solventes e economia de energia em comparação aos procedimentos de extração clássicos (ALBERO et al., 2019; CASTRO et al., 2007). O campo acústico promovido pelo ultrassom é utilizado até mesmo para catálise de reações (ALBERO et al., 2019; CHEMAT et al., 2017; TAHA et al., 2020). O potencial da energia de ultrassom pode ser aplicado para processos físicos e químicos. Os processos físicos são atribuídos principalmente aos efeitos mecânicos das ondas de alta intensidade em qualquer meio, enquanto os processos químicos se referem aos efeitos químicos induzidos pela cavitação ultrassônica em líquidos. O ultrassom pode ser efetivamente utilizado para melhorar a taxa de extração pelo aumento da transferência de massa e possível ruptura da parede celular devido à formação de microcavidades levando a maiores rendimentos do produto com reduzido tempo de processamento e consumo de solvente (HOLKAR et al., 2019; KHAN et al., 2020). Os equipamentos geradores de ultrassom mais comuns são por aplicação direta (sonda) e indireta (banho). Estes instrumentos são facilmente aplicados a processos industriais e permitem, com relativa facilidade, acoplamento em sistemas de grande escala (KULKARNI et al., 2014).

Investigações sobre a reciclagem do óleo lubrificante ferroviário usado é escasso na literatura. Óleos lubrificantes apresentam características diferentes como, por exemplo, índice de viscosidade de 99 e 160 para ferroviário e automotivo, respectivamente (valores modais de produção). Neste contexto, o objetivo 
deste estudo é a reciclagem do óleo lubrificante ferroviário usado por extração com solventes verdes assistido por uso indireto de ultrassom. Inicialmente foi determinado o parâmetro de solubilidade de Hansen do óleo lubrificante ferroviário pelo método de esfera. Utilizando informações de 1236 solventes, e um critério sustentável de seleção, foi selecionado os melhores solventes extratores. Um planejamento de misturas foi investigado utilizando os solventes selecionados. Uma mistura solvente:amostra foi submetida as condições de uso indireto de ultrassom e agitação mecânica, como controle. O óleo recuperado foi caracterizado quanto a densidade, viscosidade cinemática e índice de viscosidade.

\section{METODOLOGIA}

\section{Amostras e reagentes}

A amostra de óleo lubrificante ferroviário usado (OLUF) foi coletada em uma oficina de locomotivas e armazenada em galões de 5 litros, devidamente identificadas. Uma amostra de óleo lubrificante ferroviário novo, comercialmente disponível, foi utilizado para controle e apresentou as seguintes características: densidade de $0,8964 \mathrm{~g} \mathrm{~cm}^{-3}$ a $20^{\circ} \mathrm{C}$; viscosidade cinemática de $150,6 \mathrm{~mm}^{2} \mathrm{~s}^{-1}$ a $40{ }^{\circ} \mathrm{C}$ e $14,4 \mathrm{~mm}^{2} \mathrm{~s}^{-1}$ a $100{ }^{\circ} \mathrm{C}$; e índice de viscosidade (IV) de 93.

Todos os reagentes utilizados foram grau analítico. Na determinação do parâmetro de solubilidade foram utilizados os solventes: acetato de etila (99,5\%, Vetec), monoetanolamina (99,0\%, Vetec), dimetilformamida (99,8\%, Vetec), diclorometano (99,5\%, Isofar), éter etílico (99,5\%, Dinâmica), dimetilsulfóxido (99,9\%, Vetec), etilenodiamina (99,0\%, Vetec), clorofórmio (99,8\%, Anidrol), metanol (99,8\%, Isofar), isobutanol (99,5\%, Dinâmica), acetato de butila (99,5\%, Vetec), acetofenona (99,0\%, Vetec), benzeno $(99,5 \%$, Vetec), ciclo-hexanol $(99,0 \%$, Vetec), 1,4-dioxano $(99,0 \%$, Vetec), tetraidrofurano $(99,0 \%$, Isofar), tolueno (99,0\%, Neon), hexano (99,0\%, Merck), piridina (99,5\%, Neon), piperidina (99,0\%, Dinâmica), ácido fórmico (99,0\%, Dinâmica), etanol (99,5\%, T.J. Baker), acetonitrila (99,0\%, Vetec), ciclo-hexano (99,0\%, Dinâmica) e metil etil cetona (MEK) $(99,5 \%$, Vetec). Para extração do óleo recuperado foram utilizados os solventes: isobutanol (99,0\%, Synth), 1-butanol (99,5\%, Dinâmica) e metil etil cetona (MEK) (99,0\%, Synth).

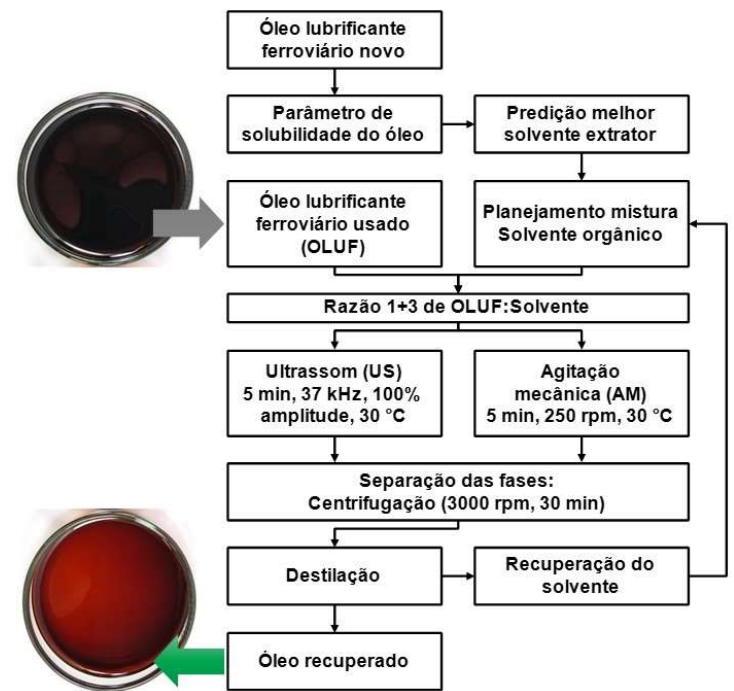

Figura 1: Procedimento experimental para extração de óleo em amostras de óleo lubrificante ferroviário usado (OLUF). 
A Figura 1 apresenta o procedimento experimental para extração de óleo em amostra de óleo lubrificante ferroviário usado.

\section{Preparo das amostras}

A amostra de OLUF, armazenado em galões de 5 litros, foi imergido parcialmente em um tanque com água a $60 \pm 5{ }^{\circ} \mathrm{C}$, onde permaneceu por 10 minutos. Em seguida, os galões foram homogeneizados manualmente por 5 minutos e a amostra foi separada em garrafas plásticas de $300 \mathrm{~mL}$, previamente higienizadas e identificadas.

\section{Determinação do parâmetro de solubilidade do óleo}

Os parâmetros de solubilidade de Hansen do óleo podem estimar o melhor solvente para proceder com a extração líquido-líquido do óleo lubrificante. Essa estimativa é calculada pela distância entre o centro da esfera de solubilidade do óleo e os parâmetros de solubilidade do solvente, conforme Equação (2), sendo $\delta_{\mathrm{D} 1}, \delta_{\mathrm{P} 1}$ e $\delta_{\mathrm{H} 1}$ as coordenadas do centro da esfera de solubilidade do óleo e $\delta_{\mathrm{D} 2}, \delta_{\mathrm{P} 2}$ e $\delta_{\mathrm{H} 2}$ as coordenadas do solvente. Se Ra for menor que o raio da esfera de solubilidade (Ro), o solvente é considerado um bom solvente extrator (HANSEN, 2007).

$$
\mathrm{Ra}=\sqrt{4\left(\delta_{\mathrm{D} 2}-\delta_{\mathrm{D} 1}\right)^{2}+\left(\delta_{\mathrm{P} 2}-\delta_{\mathrm{P} 1}\right)^{2}+\left(\delta_{\mathrm{H} 2}-\delta_{\mathrm{H} 1}\right)^{2}}
$$

Os testes de solubilidade foram realizados com cada solvente tal como recebido do fabricante. Em frascos transparentes com capacidade de $15 \mathrm{~mL}$, foram adicionados, com auxílio de uma pipeta graduada, 5 $\mathrm{mL}$ de solvente e 0,5 g de óleo lubrificante ferroviário novo e em seguida fez-se uma agitação manual por 2 minutos. A mistura ficou em repouso, à temperatura de $25^{\circ} \mathrm{C}$, por $24 \mathrm{~h}$. Ao final desta condição, foi realizado uma inspeção visual dos frascos para avaliar a solubilidade. Foi considerado insolúvel aquele frasco que apresentava separação de fases. Como critério de quantificação, foi atribuído o valor arbitrário de "1" para a mistura solvente/óleo solúvel, e o valor arbitrário "0" para a mistura insolúvel. Após avaliar todos os solventes, foi utilizado o software HSPiP $5.3 .02^{1}$ (2020) para plotar a zona de solubilidade do óleo e determinar os parâmetros de solubilidade.

\section{Critério para escolha do solvente extrator}

Foi desenvolvido uma métrica para a escolha do melhor solvente extrator, utilizando os seguintes critérios: (1) esfera de solubilidade; (2) propriedade dos solventes; (3) declaração de perigo dos solventes. $O$ resultado obtido para a esfera de solubilidade (item 2.3) do óleo comercial foi utilizado como primeiro critério de escolha do solvente extrator adequado para extração do óleo da amostra de lubrificante ferroviário usado.

O segundo critério utilizou propriedades dos solventes: ponto de ebulição (Teb); ponto de fusão (Tf); logaritmo do coeficiente de partição octanol/água (log Kow); a fórmula molecular do solvente entre 3 e 5

${ }^{1}$ www.hansen-solubility.com 
átomos de carbono (sendo não cíclico ou aromático). Foram utilizadas as informações de 1236 solventes que constavam no banco de dados do software HSPiP 5.3.06² (2020).

O terceiro critério avaliou a toxidade dos solventes. A toxicidade foi definida com base nas declarações de perigo da Globally Harmonized System (GHS). Foram atribuídos valores arbitrários de acordo com o risco físico (H225 e H226), a saúde (H300, H301, H302, H303, H310, H311, H312, H314, H315, H316, H317, H318, H319, H320, H330, H331, H332, H333, H340, H341, H350 e H351), ao meio ambiente (H400, H401, H402, H410, H411 e H412) e aos pictogramas inflamável (GHS02), corrosivo (GHS05), tóxico (GHS06), irritante (GHS07), risco a saúde (GHSO8) e risco ao meio ambiente (GHSO9). Foi atribuído valor arbitrário "1" para GHSO2, GHSO5, GHSO7, H226, H303, H316, H320 e H333; valor arbitrário "2" para H225, H302, H312, H315, H317 e H332; valor arbitrário “3" para H318 e H319; valor arbitrário “4" para GHS06, H301, H311, H314 e H331, valor arbitrário "6" para GHS08, H300, H310, H330, H402 e H412; valor arbitrário "8" para GHS09, H341, H351, H401 e H411; valor arbitrário "10" para H340 e H350; e valor arbitrário "12" para H400 e H410. Quando o solvente não apresentou o risco, foi atribuído valor arbitrário "0". Os riscos associados a mutagenicidade, carcinogenicidade e riscos ao meio ambiente, devido à gravidade que representam, receberam os maiores valores. Ao final, os valores atribuídos a cada solvente foram somados e normalizados em uma escala de 0 a 100 . Solventes que apresentaram valor de toxicidade menor que 15 foram considerados limpos e com potencial reduzido de danos ao ser humano e ao meio ambiente. As declarações de risco dos solventes e aplicabilidade na indústria, foram consultadas no site PubChem ${ }^{3}$. O fluxograma para decidir o solvente extrator adequado pode ser observado na Figura 2.

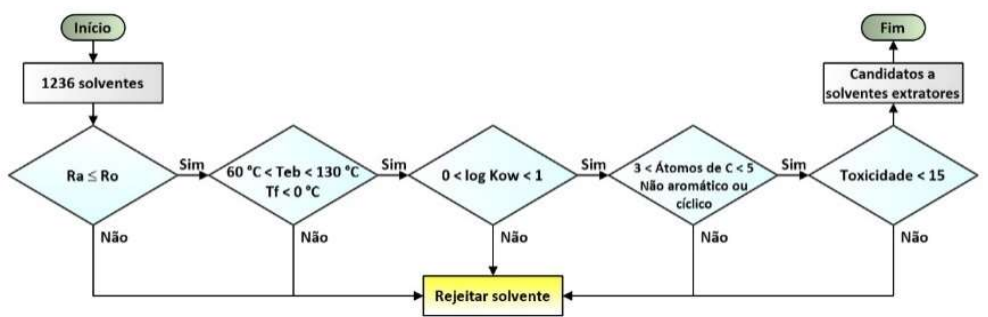

Figura 2: Fluxograma para escolha do solvente extrator adequado para extração do óleo da amostra de lubrificante ferroviário usado (OLUF). Ro: raio da esfera de solubilidade do óleo lubrificante ferroviário; Ra: distância entre o centro da esfera de solubilidade do óleo e o parâmetro de solubilidade do solvente; Teb: ponto de ebulição do solvente; Tf: ponto de fusão do solvente; Kow: coeficiente de partição octanol/água do solvente.

\section{Planejamento experimental de mistura de solventes}

Para avaliar o solvente mais adequado para utilizar no processo de extração de óleo por uso de ultrassom indireto foi proposto um planejamento experimental da mistura dos solventes orgânicos polares isobutanol, 1-butanol e MEK. Utilizando o software Statistica ${ }^{\text {TM }} 13.0$ (Stat Soft, Inc., 2019) foi elaborado um planejamento experimental de mistura Simplex-lattice [3, 3]. A mistura de solvente e OLUF foi preparada em béquer de $250 \mathrm{~mL}$ de vidro, adicionando $30 \mathrm{~g}$ da mistura de solventes (conforme gerado pelo planejamento) e $10 \mathrm{~g}$ de OLUF (razão Solvente:OLUF de 3+1).

\footnotetext{
${ }^{2}$ www.hansen-solubility.com

${ }^{3}$ http://pubchem.ncbi.nlm.nih.gov/
} 


\section{Procedimento de recuperação de óleo}

O solvente orgânico polar foi adicionado ao OLUF e seguiu-se a aplicação de ultrassom indireto (12 L, Elma, Alemanha) com baixa frequência ( $37 \mathrm{kHz}$ ). Foram fixados os seguintes parâmetros: (i) tempo de aplicação de $5 \mathrm{~min}$; (ii) frequência de $37 \mathrm{kHz}$; (iii) temperatura de $30^{\circ} \mathrm{C}$; e (iv) potência ultrassônica de $100 \%$ (SOUZA, 2015). Para teste controle, foi avaliado a extração utilizando agitador mecânico de hélice modelo RW 20 (IKA, Alemanha) a $250 \mathrm{rpm}$ por 5 min e temperatura de $30^{\circ} \mathrm{C}$.

Após o procedimento de extração solvente/OLUF, as amostras foram centrifugadas a $3000 \mathrm{rpm}$ por 30 min em centrifuga modelo SL-700 (Solab, Brasil) para a separação das fases. Em seguida, a fase topo (solvente e óleo recuperado) foi adicionada em balão fundo redondo de $250 \mathrm{~mL}$ e levado para destilação a vácuo em um evaporador rotativo modelo M802 (Fisatom, Brasil). Ao término da destilação, o balão foi levado à peso constante e o óleo, finalmente, transferido para um frasco para caracterização. Posteriormente ao processo de peso constante, o cálculo do rendimento foi feito pela relação entre a massa de óleo recuperado na destilação ( $m_{\text {recuperado }}$ e a massa de OLUF adicionada inicialmente ao processo (moluf), como mostra a Equação (3).

$$
\text { Rendimento }(\%)=\left(\frac{\mathrm{m}_{\text {recuperado }}}{\mathrm{m}_{\mathrm{OLUF}}}\right) \cdot 100
$$

\section{Caracterização do óleo recuperado}

Após o procedimento de extração, a qualidade do óleo recuperado foi avaliada pela densidade, viscosidade cinemática e Índice de Viscosidade. A densidade foi determinada de acordo com o método normatizado ASTM D4052-18a (ASTM, 2018) usando o densímetro digital modelo DMA 4500 M (Anton Paar, Áustria) com uma resolução de $0,00001 \mathrm{~g} \mathrm{~cm}^{-3}$ e faixa de temperatura de 0 a $100{ }^{\circ} \mathrm{C}$ Com auxílio de um seringa, o óleo recuperado ( $5 \mathrm{~mL}$ ) foi inserido no tubo de amostra do analisador no formato U. A temperatura foi mantida constante durante a determinação.

Para determinação da viscosidade cinemática, inicialmente foi determinada a viscosidade dinâmica a 40, 60, 80 e $100{ }^{\circ} \mathrm{C}$ usando o reômetro MCR 72 (Anton Paar, Áustria) com spindle CC27. A densidade também foi determinada nas mesmas temperaturas no densímetro modelo DMA $4500 \mathrm{M}$. A viscosidade cinemática $(v)$ foi obtida dividindo a viscosidade dinâmica $(\mu)$ pela densidade $(\rho)$ na mesma temperatura. $O$ Índice de Viscosidade (IV) foi calculado pela norma ASTM D2270-10 (ASTM, 2016), utilizando o resultado da viscosidade cinemática do óleo a $40^{\circ} \mathrm{C}$ e a $100^{\circ} \mathrm{C}$.

\section{Análise estatística}

Os resultados das amostras obtidos com uso de ultrassom e o teste controle (agitação mecânica) com diferentes solventes (isobutanol, 1-butanol e MEK) foram analisados quando à significância estatística por análise de variância (ANOVA) e teste post hoc de Tukey HSD $(p<0,05)$ conduzidos no software Statistica' 13.0 (Stat Soft, Inc., 2019). 


\section{RESULTADOS E DISCUSSÃO}

\section{Determinação do parâmetro de solubilidade do óleo ferroviário comercial}

Na literatura são escassos os trabalhos que estimaram o parâmetro de solubilidade de Hansen para óleos lubrificantes. Óleos ferroviários é um óleo predominantemente mineral elaborado para motores diesel. Os trabalhos envolvendo parâmetro de solubilidade de óleos, em sua maior parte utilizam cálculos ou correlações ou estimam apenas o parâmetro de solubilidade total $\left(\delta_{\mathrm{T}}\right)$. Voelkel et al. (2014), por exemplo, utilizou correlações para determinar o parâmetro de solubilidade de Hansen de óleos básicos minerais e encontraram valores médios para $\delta_{\mathrm{D} 1}$ de $16,4 \mathrm{MPa}^{0.5}, \delta_{\mathrm{P} 1}$ de $4,6 \mathrm{MPa}^{0.5}$ e $\delta_{\mathrm{H} 1}$ de 7,0 $\mathrm{MPa}^{0.5}$ resultando em $\delta_{\mathrm{T}}$ de 18,4 MPa ${ }^{0.5}$. Já Pinheiro et al. (2018), no estudo de regeneração de óleo lubrificante usado, utilizou um valor médio para $\delta_{\mathrm{T}}$ de $18,0 \mathrm{MPa}^{0.5}$. Outros autores, como o caso de (YANG et al., 2013), no utilizou $\delta_{\mathrm{T}}$ aproximado como sendo de $15,5 \mathrm{MPa}^{0.5}$ que corresponde ao parâmetro de solubilidade do poliisobutileno, um aditivo geralmente introduzido em óleos lubrificantes como melhorador do Índice de Viscosidade. Levin et al. (2008) foi além e utilizou a metodologia proposta por Hansen para determinar o parâmetro de solubilidade de Hansen para um hidrocarboneto sintético do tipo parafínico (representa um óleo refinado severamente com nenhum conteúdo aromático e sem heteroátomos), um óleo naftênico severamente hidrotratado e um destilado naftênico com alto conteúdo aromático. O parâmetro de solubilidade $\delta_{\mathrm{D} 1}$, $\delta_{\mathrm{P} 1}$ e $\delta_{\mathrm{H} 1}$ determinado para o óleo naftênico foi 17,2, 3,0 e 5,3 MPa ${ }^{0.5}$, respectivamente (LEVIN et al., 2008).

Para estabelecer o parâmetro de solubilidade de Hansen para óleo lubrificante ferroviário novo, foi utilizado uma métrica atribuindo valores arbitrários ("0": insolúveis; "1": solúveis) para a inspeção visual dos frascos (Figura 3).

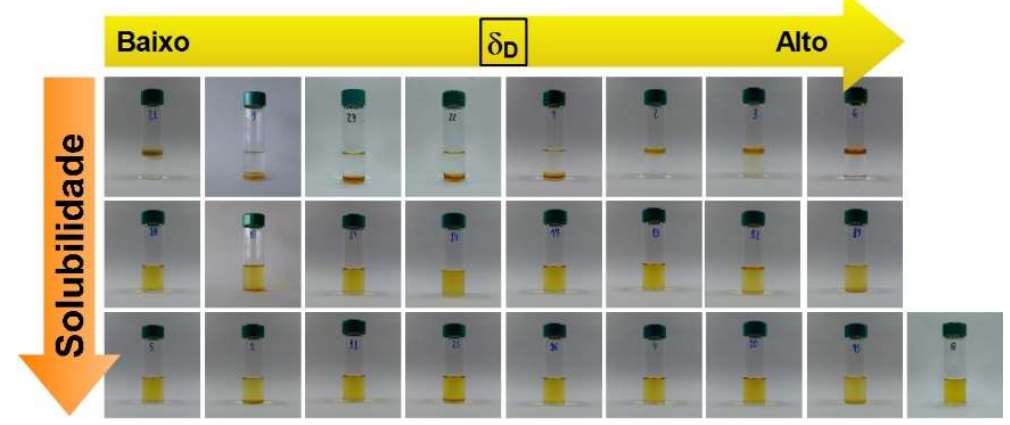

Figura 3: Parâmetro de dispersão de Hansen do óleo lubrificante ferroviário novo com vários solventes orgânicos. Os solventes são: (1) acetato de etila, (2) monoetanolamina, (3) dimetilformamida, (4) diclorometano, (5) éter etílico, (6) dimetilsulfóxido, (7) etilenodiamina, (8) clorofórmio, (9) metanol, (10) isobutanol, (11) acetato de butila, (12) acetofenona, (13) benzeno, (14) ciclo-hexanol, (15) 1,4-dioxano, (16) tetraidrofurano, (17) tolueno, (18) hexano, (19) piridina, (20) piperidina, (21) ácido fórmico, (22) etanol, (23) acetonitrila, (24) ciclo-hexano, (25) metil etil cetona (MEK).

Foi observado solventes totalmente, parcialmente e pouco miscíveis ao óleo ferroviário novo. Foram considerados solventes insolúveis: monoetanolamina; dimetilformamida; dimetilsulfóxido; etilenodiamina; metanol; ácido fórmico; etanol; e acetonitrila. Os solventes considerados solúveis, de acordo com a análise qualitativa, foram: acetato de etila, diclorometano, éter etílico, clorofórmio, isobutanol, acetato de butila, acetofenona, benzeno, ciclo-hexanol, 1,4-dioxano, tetraidrofurano, tolueno, hexano, piridina, piperidina, 
ciclo-hexano, e metil etil cetona (MEK).

Os resultados quantificados da inspeção visual foram utilizados para determinar o parâmetro de solubilidade do óleo lubrificante ferroviário novo e representados pela esfera de solubilidade. Os solventes classificados como solúveis são localizados no interior da esfera de solubilidade, e aqueles com baixa solubilidade, são representados na parte externa da esfera (Figura 4). 0 resultado para o parâmetro de dispersão de Hansen do óleo lubrificante ferroviário novo $\left(\delta_{\mathrm{D} 1}\right)$ foi $15,8 \mathrm{MPa}^{0.5}$, polar $\left(\delta_{\mathrm{P} 1}\right)$ de $3,8 \mathrm{MPa}^{0.5} \mathrm{e}$ de ligação de hidrogênio $\left(\delta_{\mathrm{H} 1}\right)$ de $7,6 \mathrm{MPa}^{0.5}$, além do raio da esfera de solubilidade Ro $=8,7$.

Aplicando estes dados na Equação (1), obteve-se um parâmetro de solubilidade total $\left(\delta_{\mathrm{T}}\right)$ de 17,9 $\mathrm{MPa}^{0.5}$. Estes valores são corroborados por outros autores (PINHEIRO et al., 2018; VOELKEL et al., 2014).

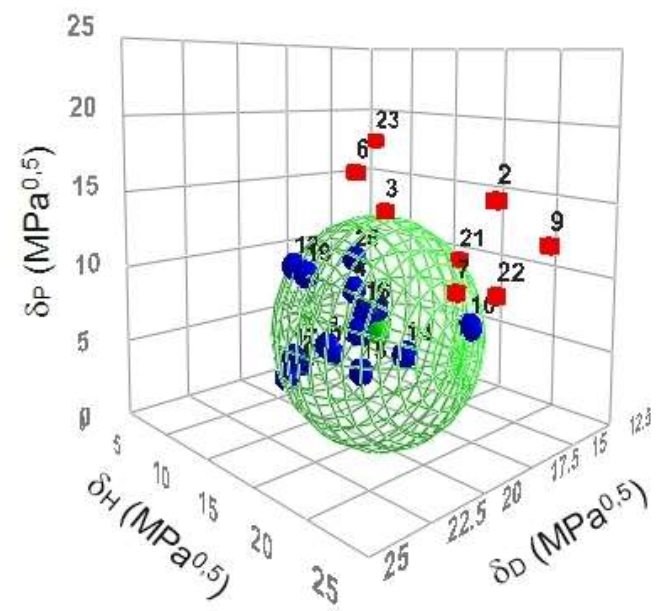

Figura 4: Esfera tridimensional do parâmetro de solubilidade de Hansen para seleção de solvente para extração do óleo lubrificante ferroviário novo. Os pontos azuis dentro da esfera solubilizam o óleo lubrificante ferroviário e os quadrados externos não a solubilizam. Solventes solúveis (círculos azuis): (1) acetato de etila, (4) diclorometano, (5) éter etílico, (8) clorofórmio, (10) isobutanol, (11) acetato de butila, (12) acetofenona, (13) benzeno, (14) ciclo-hexanol, (15) 1,4-dioxano, (16) tetraidrofurano, (17) tolueno, (18) hexano, (19) piridina, (20) piperidina (24) ciclo-hexano, (25) metil etil cetona (MEK). Solventes com baixa solubilidade (retângulos vermelhos): (2) monoetanolamina, (3) dimetilformamida, (6) dimetilsulfóxido, (7) etilenodiamina, (9) metanol, (21) ácido fórmico, (22) etanol e (23) acetonitrila.

A maior contribuição para o parâmetro de solubilidade de Hansen determinado para o óleo lubrificante ferroviário é o parâmetro de dispersão $\left(15,8 \mathrm{MPa}^{0.5}\right)$. Esse parâmetro é intensificado pela presença de hidrocarbonetos alifáticos saturados, justificado pelo fato do óleo lubrificante englobar misturas de longas cadeias de hidrocarbonetos saturados com cadeia carbônica que pode variar de 15 a 50 átomos de carbono (HANSEN, 2007).

\section{Otimização do solvente extrator}

A avaliação de processos "verde" de extração tem atraído o interesse de pesquisadores. Várias ferramentas para medir o Índice de Procedimento Analítico Verde tem sido proposta por diferentes autores para avaliar o caráter verde de uma metodologia analítica/de extração, desde a coleta de amostra até a determinação final (PENA-PEREIRA et al., 2020; PŁOTKA-WASYLKA, 2018). Estes índices avaliam o impacto ambiental (baixo, médio e alto) e cada etapa de uma metodologia analítica de extração. Coleta e preparo de amostra, reagentes e solvente usados no processo, tipo de método, instrumentação, são importantes 
parâmetros utilizados nestas métricas de avaliação "verde". Conforme descrito por Sánchez-Camargo et al. (2019), a utilização do método parâmetros de solubilidade de Hansen pode ajudar a melhorar o caráter verde do processo, pois reduzem o desperdício de recursos e tempo para a seleção da extração do solvente.

Contribuindo para um processo "verde", a recuperação de óleo assistido por ultrassom em amostra de óleo lubrificante usado, é uma alternativa viável pois não produz resíduos ainda mais tóxicos como os métodos tradicionais (CHEMAT et al., 2020; JAFARI et al., 2015). Entretanto, no processo de extração é utilizado solventes orgânicos e para mitigar o processo, optou-se por utilizar uma métrica para escolha do melhor solvente extrator com menor impacto. Foi utilizado informações de 1236 solventes que constavam no banco de dados do software HSPiP 5.3.02 (ABBOTT et al., 2015) e os resultados de solubilidade do óleo lubrificante ferroviário novo. A partir dos resultados da esfera de solubilidade do óleo lubrificante ferroviário novo e utilizando propriedades como ponto de ebulição (Teb), ponto de fusão (Tf), logaritmo do coeficiente de partição octanol/água (log Kow) e a fórmula molecular dos solventes foi possível predizer qual o melhor solvente para ser utilizado nos testes de extração de óleo recuperado do OLUF.

Analisando a esfera tridimensional de HPS, solventes que apresentam potencial de solubilizar o óleo básico devem estar contidos no interior da esfera de solubilidade, ou seja, apresentar distância entre o centro da esfera de solubilidade do óleo até o parâmetro de solubilidade do solvente (Ra) menor que o raio da esfera de solubilidade (Ro). Como Ro foi de 8,7, essa métrica foi definida como Ra menor ou igual a 8,7. Adotando este critério, o conjunto de 1236 solventes candidatos foi reduzido a 800 solventes, sendo rejeitado solventes como etanol, metanol, água e isopropanol.

A temperatura é uma critério importante uma vez que define a escolha por solventes que sejam líquidos a temperatura ambiente (PINHEIRO et al., 2018). Considerando que uma das etapas do processo de extração líquido-líquido é a recuperação do solvente no processo de destilação, ponto de ebulição acima de $130{ }^{\circ} \mathrm{C}$ podem dificultar a recuperação do solvente. $\mathrm{O}$ critério de temperatura de ebulição (Teb), foi definido como valores ideais entre $60^{\circ} \mathrm{Ce} 130{ }^{\circ} \mathrm{C}$, e a temperatura de fusão (Tf), valores menores que $0{ }^{\circ} \mathrm{C}$. Seguindo esse critério, os 800 solventes candidatos escolhidos anteriormente foram reduzidos para 203 solventes. Solventes como etileno, ciclo-hexanol, acetona, pentanol e xileno foram rejeitados nessa métrica.

O logaritmo do coeficiente de partição octanol/água (log Kow) também foi utilizado como critério de escolha do solvente. $O$ coeficiente de partição octanol/água é definido como a razão entre a concentração de um produto químico na fase de octanol e sua concentração na fase aquosa de um sistema bifásico octanol/água. O Kow desempenha um papel importante como indicador ecológico e bioquímico pois contribui na determinação da distribuição e destino de contaminantes orgânicos no meio ambiente (TOROPOV et al., 2015; ZENG et al., 2012). Adotou-se como valor ótimo o solvente que apresentou valores de log Kow entre 0 e 1. Quando log Kow < 0 indica que a maior concentração do solvente está na água quando em um ambiente bifásico aquoso/orgânico sendo, portanto, considerado solvente pobre para a extração de óleo lubrificante tendo em vista o caráter predominantemente orgânico do óleo. Solventes como butadiona, 1,3-dioxolano e brometo de acetila apresentaram log Kow $<0$ e foram rejeitados. Quando o solvente apresenta log Kow > 1 já pode ser considerado muito hidrofóbico, o que não é adequando para a segregação 
entre óleo básico e contaminantes. Além disso, quando $\log \mathrm{Kow}>2$, o solvente possui potencial de bioconcentrar nas cadeias alimentares terrestres, inclusive em humanos, e quando log Kow $>4,5$ esse potencial de bioacumulução do solvente expande-se para os organismos aquáticos (ABBOTT et al., 2015; ECHA, 2017). Utilizando o critério de log Kow > 1, foi possível rejeitar 147 solventes candidatos como por exemplo 2-pentanol, clorofórmio, tolueno e heptan. O número de candidatos passou de 203 solventes para 56 solventes.

A fórmula molecular dos solventes também é um importante parâmetro a ser utilizado na escolha do solvente. De acordo com Reis et al. (1990) e Pinheiro et al. (2018), a capacidade de um solvente de segregar óleo básico e contaminantes está relacionada com o tamanho de sua cadeia carbônica. Solventes com menos de 3 átomos de carbono apresentam baixa eficiência de segregação enquanto que solventes com mais de 5 átomos de carbono apresentam bons rendimentos de recuperação do óleo básico, porém, com baixa qualidade devido a capacidade desses solventes em solubilizar componentes mais pesados no OLUF (PINHEIRO et al., 2018; REIS et al., 1990; RINCÓN et al., 2005). Outro ponto relacionado a fórmula do solvente é a presença de estruturas cíclicas ou aromáticas. Como os óleos lubrificantes apresentam estrutura predominantemente de hidrocarbonetos alifáticos complexos com baixo conteúdo de aromáticos, caso o solvente que apresente estruturas cíclicas ou aromáticas seja utilizado na recuperação do óleo, pode favorecer a recuperação de óleo com baixa qualidade e alto teor de aromáticos, como os contaminantes hidrocarbonetos policíclicos aromáticos (HPA). Além disso, estruturas cíclicas e aromáticas contribuem para a toxicidade do solvente, o que não é desejável (GOEL et al., 2018; MCKEE et al., 2015; SPEIGHT et al., 2014). Analisando os 56 solventes candidatos, foram selecionados os aqueles que não apresentavam estrutura cíclica ou aromática, entre 3 e 5 átomos de carbono. Os resultados mostraram que apenas 30 dos 56 solventes atendiam ao critério. Solventes como o ácido tioacético, dicloroacetonitrila, cloroformato de metila, piridina e tetraidrofurano foram excluídos como candidatos.

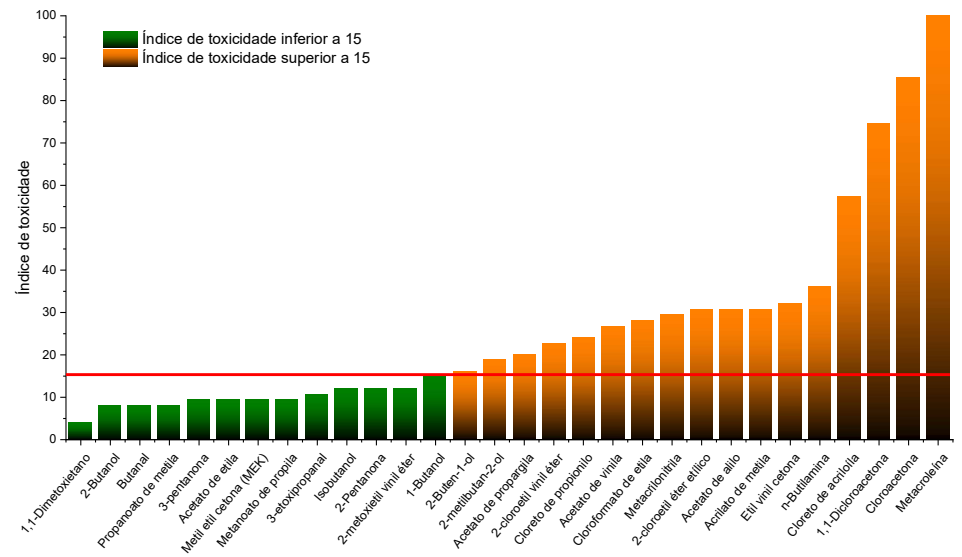

Figura 5: Índice de classificação dos solventes quanto ao risco físico, à saúde, e ao meio ambiente. Linha vermelha representa o limite (valor arbitrário acima de 15) para rejeitar os solventes considerados muito tóxicos.

Considerando eliminar solventes considerados tóxicos ao meio ambiente e ao ser humano, procedese a classificação do grupo de 30 solventes restantes. Os resultados mostraram que os 30 solventes apresentaram risco físico associado a inflamabilidade (H225 ou H226). Solventes, como cloroacetona e 1,1- 
dicloroacetona, são classificados como muito tóxicos para a vida aquática (H400 e H410) e foram rejeitados. A metacroleína além de ser tóxica para a vida aquática, também é um solvente suspeito de causar defeitos genéticos (H341). Já o acetato de vinila foi rejeitado por ser suspeito de causar câncer (H351). Outros exemplos de solventes como álcool terc-amílico, butilamina e metil vinil cetona foram rejeitados, e o número de solventes foi reduzido para 13 candidatos (Figura 5). Os resultados de parâmetro de solubilidade, Ra, ponto de ebulição e fusão, LogKow, número de átomos de carbono e toxicidade estão apresentados na Erro!

\section{Fonte de referência não encontrada.}

O grupo de 13 solventes candidatos a solvente extrator foram analisados quando a utilização na indústria. Os solventes 1,1-Dimetoxietano, 2-butanol, Propanoato de metila, 2-pentanona, 3-pentanona, Metanoato de propila, Butanal e Acetato de etila são largamente utilizados como agentes, aromatizantes e aditivos de melhoria alimentar (BURDOCK, 2010; LEWIS et al., 2016). O isobutanol é usado principalmente como solvente em revestimentos de superfícies e adesivos e intermediário nas indústrias de aromas e fragrâncias, farmacêutica e de pesticidas. O solvente 1-Butanol também é usado como solvente em revestimentos de superfícies, que inclui vernizes, resinas e ceras. Metil etil cetona é usado principalmente como solvente em tintas, revestimentos, colas e tintas de impressão, fluidos de limpeza e como matériaprima para fazer outros produtos químicos (LEWIS et al., 2016; WILEY-VCH, 2011). O 2-metoxietil vinil éter é aplicado em polímeros industriais (HASHIMOTO et al., 2010; SUGIHARA et al., 2013). Poucas informações foram encontradas sobre o 3-ethoxypropanal, sendo encontrado em processos de fermentação de uísques (AYLOTT et al., 1994).

A aplicabilidade dos solventes isobutanol, 1-butanol e MEK foi usada como critério de seleção para o planejamento de misturas de solventes. Além disso, esses solventes são difundidos como bons solventes extratores (DAHAM et al., 2017; KAMAL et al., 2009; YANG et al., 2013).

Tabela 1: Resultados dos solventes selecionados pelos critérios de parâmetro de solubilidade, Ra, ponto de ebulição e fusão, LogKow, número de átomos de carbono e toxicidade.

\begin{tabular}{|c|c|c|c|c|c|c|c|c|c|c|}
\hline \multirow[t]{2}{*}{ Solventes } & $\delta_{\mathrm{D}}$ & $\delta_{\mathrm{P}}$ & $\delta_{\mathrm{H}}$ & $\delta_{\mathrm{T}}$ & $\mathrm{Ra}$ & \multirow{2}{*}{$\begin{array}{l}\text { Ebulição } \\
\left({ }^{\circ} \mathrm{C}\right)\end{array}$} & \multirow{2}{*}{$\begin{array}{l}\text { Fusão } \\
\left({ }^{\circ} \mathrm{C}\right)\end{array}$} & \multirow[t]{2}{*}{ LogKow } & \multirow[t]{2}{*}{ Átomos de C } & \multirow[t]{2}{*}{ Índice de Toxicidade } \\
\hline & \multicolumn{5}{|c|}{$\left(\mathrm{MPa}^{0.5}\right)$} & & & & & \\
\hline 1,1-Dimetoxietano & 15,1 & 4,9 & 4,9 & 16,6 & 3,2 & 64,0 & $-113,0$ & 0,22 & 4 & 4,0 \\
\hline 1-Butanol & 16,0 & 5,7 & 15,8 & 23,2 & 8,4 & 118,0 & $-89,0$ & 0,88 & 4 & 14,7 \\
\hline 2-Butanol & 15,8 & 5,7 & 14,5 & 22,2 & 7,2 & 100,0 & $-115,0$ & 0,61 & 4 & 8,0 \\
\hline 2-metoxietil vinil éter & 15,9 & 6,7 & 6,8 & 18,5 & 3,0 & 106,5 & $-89,0$ & 0,16 & 5 & 12,0 \\
\hline 2-Pentanona & 16,0 & 7,6 & 4,7 & 18,3 & 4,8 & 102,0 & $-77,0$ & 0,91 & 5 & 12,0 \\
\hline 3-etoxipropanal & 16,0 & 8,8 & 7,4 & 19,7 & 5,0 & 129,6 & $-63,5$ & 0,40 & 5 & 10,7 \\
\hline 3-pentanona & 15,8 & 7,6 & 4,7 & 18,2 & 4,8 & 102,0 & $-39,0$ & 0,99 & 5 & 9,3 \\
\hline Acetato de etila & 15,8 & 5,3 & 7,2 & 18,2 & 1,6 & 77,0 & $-84,0$ & 0,73 & 4 & 9,3 \\
\hline Butanal & 15,6 & 10,1 & 6,2 & 19,6 & 6,5 & 75,0 & $-96,0$ & 0,88 & 4 & 8,0 \\
\hline Isobutanol & 15,1 & 5,7 & 15,9 & 22,7 & 8,6 & 108,0 & $-108,0$ & 0,76 & 4 & 12,0 \\
\hline Metanoato de propila & 15,5 & 7,1 & 8,6 & 19,1 & 3,5 & 81,0 & $-93,0$ & 0,83 & 4 & 9,3 \\
\hline Metil etil cetona (MEK) & 16,0 & 9,0 & 5,1 & 19,1 & 5,8 & 80,0 & $-87,0$ & 0,29 & 4 & 9,3 \\
\hline Propanoato de metila & 15,5 & 6,5 & 7,7 & 18,5 & 2,8 & 79,0 & $-88,0$ & 0,84 & 4 & 8,0 \\
\hline
\end{tabular}

A distância Ra entre o centro da esfera de solubilidade e os parâmetros de solubilidade de cada solvente foi calculado pela Equação (2), conforme mostra a Tabela 2. Dentre os solventes selecionados, o MEK, por apresentar menor Ra, pode ser estimado por meio do estudo dos parâmetros de solubilidade como forte candidato a apresentar a melhor capacidade de extração do óleo básico do OLUF. 
Uma vantagem do estudo dos parâmetros de solubilidade é a possibilidade de estimar parâmetros de solubilidade de mistura de solventes. Com o software HSPiP foi realizado o estudo das possíveis misturas de solventes que também podem ser consideradas promissoras na recuperação de óleo. De acordo com o software, a mistura de $70 \% \mathrm{~m} / \mathrm{m}$ de MEK com $30 \% \mathrm{~m} / \mathrm{m}$ de isobutanol pode maximizar o rendimento de extração de óleo básico do OLUF.

Tabela 2: Diferença entre o parâmetro de solubilidade de Hansen ( $\delta_{D}$ : dispersão, $\delta_{P}:$ polar, $\delta_{H}$ : ligação de hidrogênio, $\delta_{T}$ : parâmetro de solubilidade total) do óleo lubrificante e os solventes isobutanol, 1-butanol e MEK.

\begin{tabular}{lllllc}
\hline Substância & \multicolumn{1}{c}{$\delta_{\mathrm{D}}$} & $\delta_{\mathrm{P}}$ & $\delta_{\mathrm{H}}$ & $\delta_{\mathrm{T}}$ & $\mathrm{Ra}$ \\
\cline { 2 - 7 } & $\left(\mathrm{MPa}^{0.5}\right)$ & & & & \\
\hline Óleo lubrificante & 15,8 & 3,8 & 7,6 & 17,9 & $8,7^{*}$ \\
Isobutanol & 15,1 & 5,7 & 15,9 & 22,7 & 8,6 \\
1-butanol & 16,0 & 5,7 & 15,8 & 23,2 & 8,4 \\
MEK & 16,0 & 9,0 & 5,1 & 19,1 & 5,8 \\
65\% MEK + 35\% isobutanol & 15,7 & 7,8 & 9,0 & 19,7 & 4,3 \\
\hline
\end{tabular}

*Raio da esfera de solubilidade do óleo lubrificante.

\section{Planejamento experimental de mistura de solventes}

O planejamento experimental de misturas de solventes é uma ferramenta importante neste trabalho para avaliar as misturas de solventes preditas pelo parâmetro de solubilidade do óleo. A variável avaliada nesse planejamento foi o rendimento de extração de óleo recuperado com ultrassom (US), conforme superfície de resposta apresentada na Figura 6. A superfície de resposta foi ajustada com um modelo quadrático que apresentou coeficiente de determinação $\left(R^{2}\right)$ de 0,9602. O ajuste do modelo foi estatisticamente significativo com $\mathrm{p}<0,0001$ ao nível de confiança de 95\%. Da superfície de reposta observase que os solventes individualmente apresentam rendimentos crescentes de isobutanol $(64,0 \% \mathrm{~m} / \mathrm{m})$, 1 butanol $(89,1 \% \mathrm{~m} / \mathrm{m})$ e $\operatorname{MEK}(91,2 \% \mathrm{~m} / \mathrm{m})$.

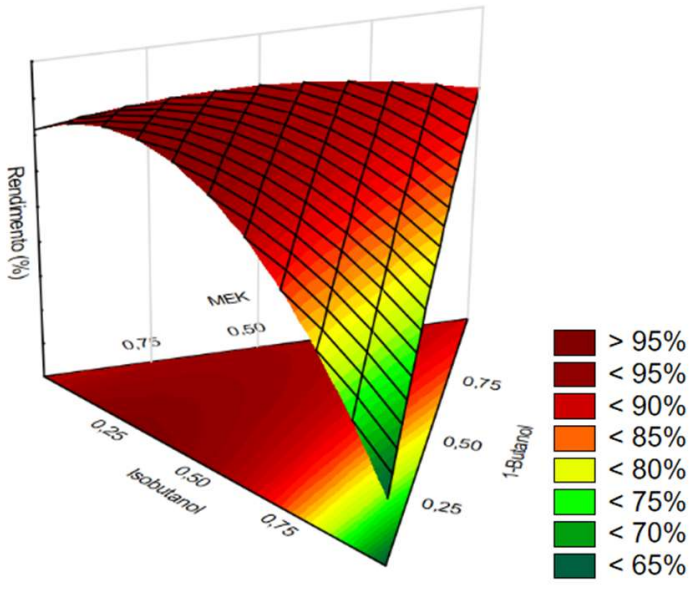

Figura 6: Superfície de resposta para as frações mássicas de isobutanol, 1-butanol e MEK no gráfico de rendimento com plotagem espacial e no plano.

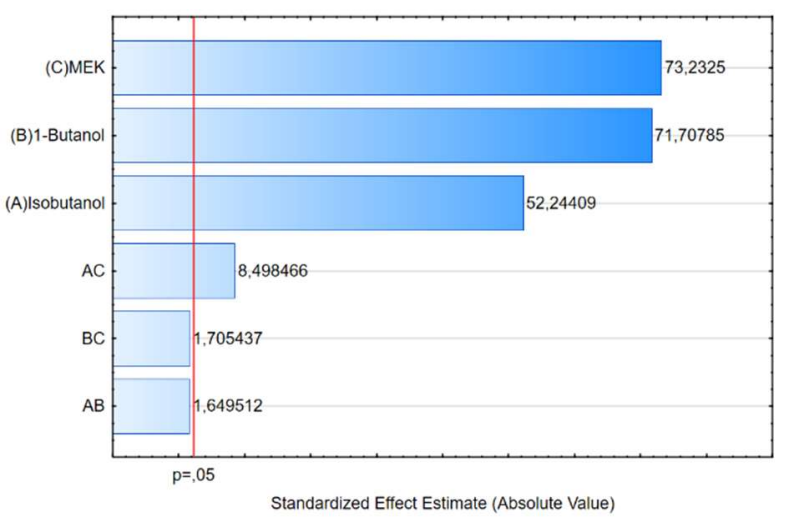

Figura 7: Diagrama de Pareto mostrando a significância da fração de cada solvente no rendimento de recuperação de óleo básico. MEK foi estatisticamente mais influente no rendimento, seguido de 1-butanol e isobutanol. O parâmetro quadrático MEK/isobutanol também foi significativamente influente.

A superfície de resposta mostrou ainda que o rendimento pode ser maximizado pela mistura mássica de 0,70 de MEK e 0,30 de isobutanol. Essa mistura, de acordo com a superfície de resposta, pode fornecer rendimentos de até $96,5 \%$. Esse resultado contribui com os resultados encontrados pelo parâmetro de 
solubilidade que indicou que a mistura mássica de 0,65 de MEK e 0,35 de isobutanol forneceria o maior rendimento uma vez que apresentou o menor Ra.

O diagrama de Pareto (Figura 7) corrobora com esse resultado indicando que o MEK foi o solvente mais influente no rendimento, seguido do 1-butanol e isobutanol, e que a mistura MEK/isobutanol também foi influente no rendimento. Os parâmetros quadráticos MEK/butanol e 1-butanol/isobutanol não foram estatisticamente significativos.

\section{Resultados de óleo recuperado por agitador mecânico e ultrassom}

Uma vez determinado o melhor solvente pelo parâmetro de solubilidade, a mistura solvente/óleo foi submetida a dois processos de extração: uso de ultrassom indireto e agitação mecânica, como controle. Os resultados dos rendimentos de recuperação de óleo obtidos com uso do ultrassom (US) e agitação mecânica (AM) foram comparados conforme apresenta a Figura 8.

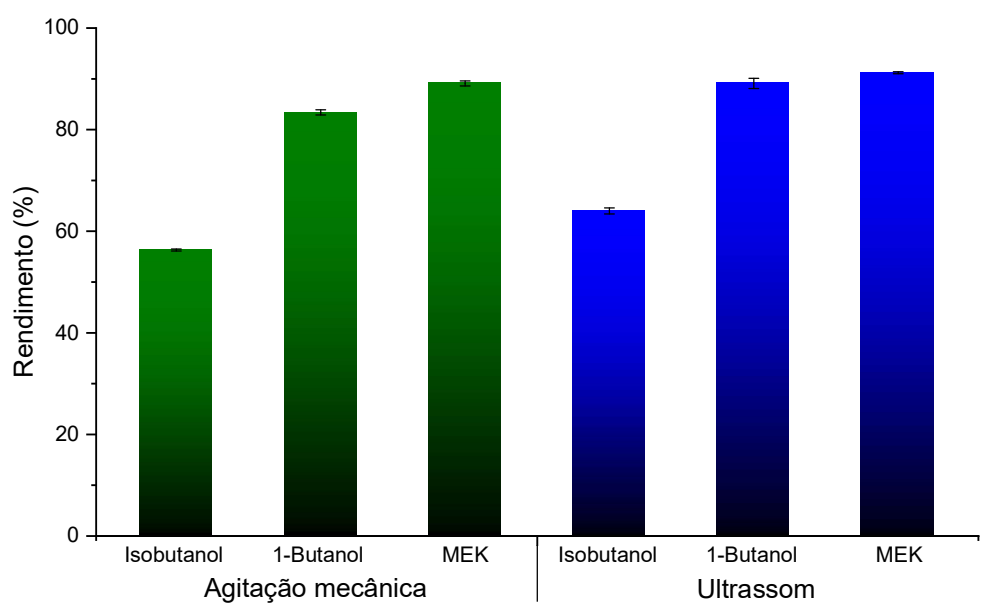

Figura 8: Rendimento de recuperação de óleo com uso de ultrassom indireto (US) e agitação mecânica (AM) para os solventes individuais: isobutanol, 1-butanol e MEK, em amostras de óleo lubrificante ferroviário usado (OLUF).

A AM apresentou rendimentos de recuperação de óleo de $56,3 \% \mathrm{~m} / \mathrm{m}, 83,4 \% \mathrm{~m} / \mathrm{m}$ e $89,1 \% \mathrm{~m} / \mathrm{m}$ para os solventes isobutanol, 1-butanol e MEK, respectivamente. Os rendimentos de recuperação de óleo usando US foram de $64,0 \% \mathrm{~m} / \mathrm{m}$ (Isobutanol), $89,1 \% \mathrm{~m} / \mathrm{m}$ (1-butanol) e $91,2 \% \mathrm{~m} / \mathrm{m}$ (MEK). A ANOVA indicou que há diferença estatisticamente significativa entre os resultados e o teste post hoc de Tukey HSD indicou que há diferença tanto entre os solventes quanto entre o US e a $A M$, ambos apresentando $p<0,0001$. A maior diferença entre os rendimentos de US e AM foi de 7,2\% $\mathrm{m} / \mathrm{m}$ para o isobutanol. $O$ teste ANOVA também foi aplicado em pares e indicou que não há diferença estatística entre o 1-butanol US e o MEK AM. Devido a pequena diferença de rendimento entre o 1-butanol e MEK, sugere-se que os solventes foram suficientes para atingir a eficiência máxima de recuperação de óleo básico. Liu et al. (2014) e Jafari et al. (2015), por exemplo, informaram que o processo de recuperação de óleo básico pode atingir rendimentos variam de $60 \% \mathrm{~m} / \mathrm{m}$ até pouco mais de $90 \% \mathrm{~m} / \mathrm{m}$, corroborando com os resultados encontrados neste trabalho.

A diferença de rendimentos entre os solventes também corrobora com os resultados encontrados 
para a esfera de solubilidade do óleo. O menor rendimento de recuperação para o isobutanol é explicado pela distância Ra entre o centro da esfera de solubilidade do óleo e o parâmetro de solubilidade do solvente que é 8,6 (Tabela 2). Como o raio da esfera do óleo determinado foi 8,7, indica que esse solvente está situado na região de contorno da esfera de solubilidade e, por isso, apresentou o menor rendimento dentre os solventes utilizados. O 1-butanol apresentou Ra de 8,4 e já apresentou rendimentos consideráveis. O MEK com o melhor rendimento, apresentou Ra de 5,8.

\section{Caracterização do óleo recuperado}

Para avaliar a qualidade dos óleos recuperados por US e AM, foram utilizados os parâmetros de densidade, viscosidade e índice de viscosidade. De acordo com Speight et al. (2014), a densidade é influenciada pela composição química do óleo. O aumento de compostos aromáticos no óleo, por exemplo, resulta em um aumento na densidade, enquanto um aumento dos compostos saturados resulta em uma redução. A densidade a $20^{\circ} \mathrm{C}$ do óleo comercial foi de $0,8964 \mathrm{~g} \mathrm{~cm}^{-3}$ e do OLUF $0,9127 \mathrm{~g} \mathrm{~cm}^{-3}$. Este resultado de densidade para o OLUF pode ser explicado por quantidades crescentes de sólidos no advindos do motor, além de contaminações de compostos oxidados e ricos em carbono ou fuligem (SPEIGHT et al., 2014).

Os resultados de densidade para óleos recuperados utilizando os solventes isobutanol, 1-butanol e MEK com uso de US foram $0,8960,0,8966$ e $0,8972 \mathrm{~g} \mathrm{~cm}^{-3}$, respectivamente, enquanto para AM, foram 0,8970, 0,8959 e 0,8968 $\mathrm{g} \mathrm{cm}^{-3}$, respectivamente (Figura 9). Os três solventes para as duas técnicas (US e AM) reduziram significativamente a densidade dos óleos recuperados, aproximando-se da densidade do óleo comercial. Ao nível de $95 \%$ de confiança, a ANOVA indicou que há diferença estatisticamente significativa entre os resultados de densidade com $p<0,0001$.

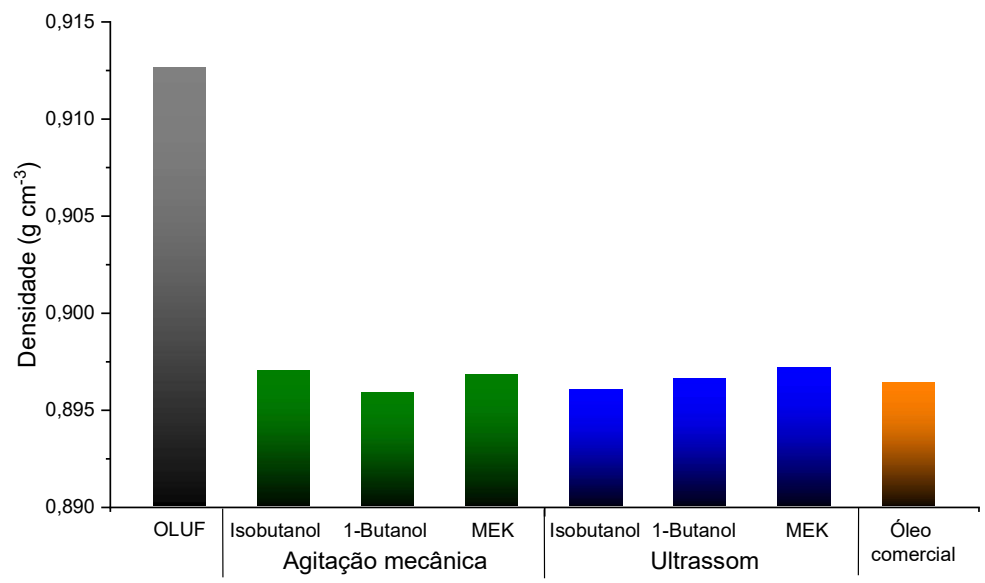

Figura 9: Densidades a $20^{\circ} \mathrm{C}$ do óleo ferroviário comercial novo, óleo recuperado após extração com ultrassom (US) e agitação mecânica (AM) para os solventes isobutanol, 1-butanol e MEK, e o óleo lubrificante ferroviário usado (OLUF).

A viscosidade é considerada a propriedade individual mais importante de um óleo lubrificante. 0 óleo lubrificante adequado para cada motor é escolhido principalmente com base na viscosidade do óleo. Para melhorar a viscosidade do óleo, produtos químicos podem ser misturados com os óleos lubrificantes para transmitir a eles certas propriedades específicas. Além disso, o teste de viscosidade pode indicar a presença de contaminação no óleo de motor usado (PINHEIRO et al., 2018; SPEIGHT et al., 2014). 
Na Figura 10 é apresentado a análise da tensão de cisalhamento $(\mathrm{Pa})$ em função da taxa de cisalhamento $\left(\mathrm{s}^{-1}\right)$ na temperatura de $40{ }^{\circ} \mathrm{C}$ para óleo comercial, OLUF e óleos recuperados. Os óleos apresentaram comportamento de fluido newtoniano uma vez que a tensão de cisalhamento aumentou linearmente com a taxa de cisalhamento. O coeficiente angular da relação tensão de cisalhamento vs taxa de cisalhamento fornece a viscosidade dinâmica das amostras a $40{ }^{\circ} \mathrm{C}$, ou seja, quanto maior a inclinação, maior a viscosidade dinâmica do óleo.

Um gráfico da viscosidade cinemática em função da temperatura foi plotado na Figura 11. O OLUF apresentou viscosidade cinemática a $40{ }^{\circ} \mathrm{C}$ de $188,7 \mathrm{~mm}^{2} \mathrm{~s}^{-1}$. A alta viscosidade do OLUF é justificada pela geração de produtos oxidados e polimerizados a partir da oxidação de aditivos presentes no óleo durante o uso no motor. Esses componentes ficam dissolvidos e suspensos no óleo causando um aumento na viscosidade do óleo (SPEIGHT et al., 2014).

O óleo ferroviário novo apresentou viscosidade cinemática a $40{ }^{\circ} \mathrm{C}$ de $150,6 \mathrm{~mm}^{2} \mathrm{~s}^{-1}$. Os óleos recuperados da amostra de óleo ferroviário usado com os solventes isobutanol, 1-butanol e MEK apresentaram, respectivamente, viscosidade cinemática a $40^{\circ} \mathrm{C}$ de $113,4,133,9$ e $143,1 \mathrm{~mm}^{2} \mathrm{~s}^{-1}$ para US e de $118,3,130,3$ e $140,0 \mathrm{~mm}^{2} \mathrm{~s}^{-1}$ para AM. O óleo recuperado com MEK/US apresentou a viscosidade mais próxima ao óleo ferroviário novo. Essa é uma característica importante uma vez que, de acordo com Speight et al. (2014), é preferível que o óleo lubrificante seja moderadamente viscoso para operar durante a partida de motores.

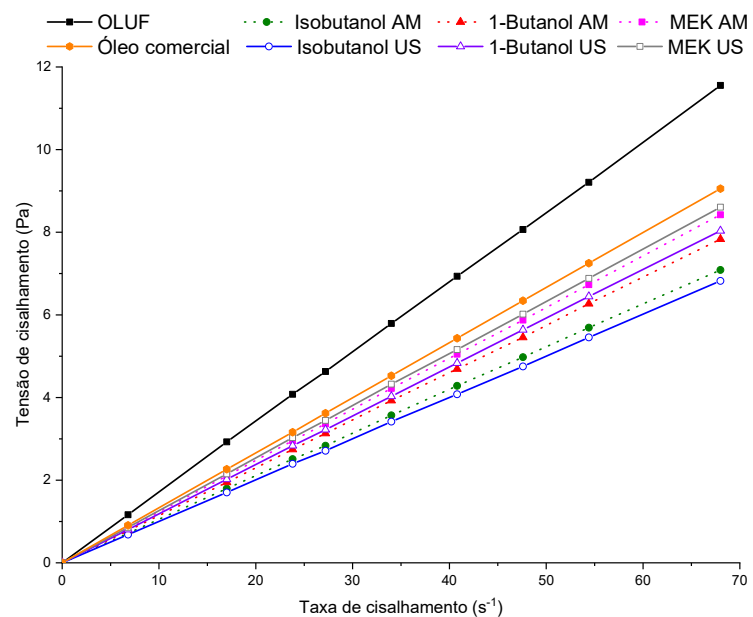

Figura 10: Tensão de cisalhamento ( $\mathrm{Pa}$ ) em função da taxa de cisalhamento $\left(\mathrm{s}^{-1}\right)$ na temperatura de $40{ }^{\circ} \mathrm{C}$ para óleo ferroviário comercial, óleo lubrificante ferroviário usado (OLUF) e óleos recuperados por extração com ultrassom (US) e agitação mecânica (AM) para os solventes isobutanol, 1-butanol e MEK.

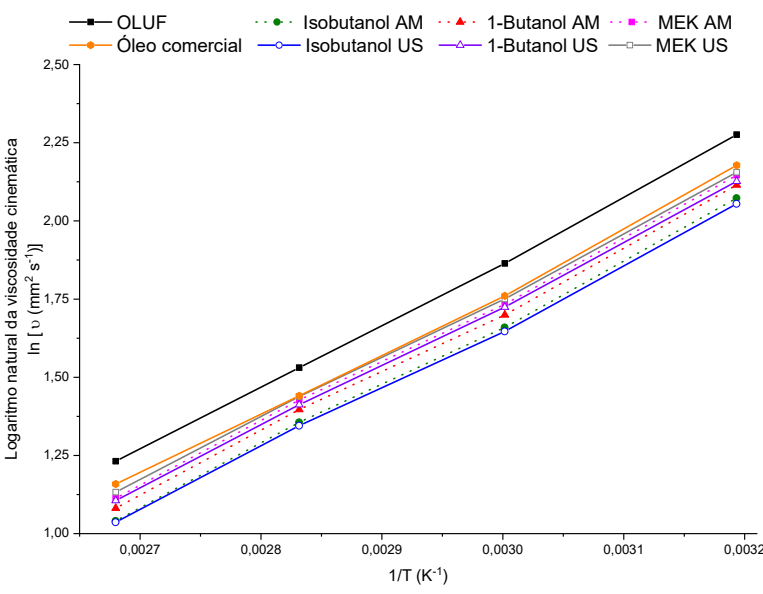

Figura 11: Logaritmo da viscosidade cinemática $(\ln v)$ em função do inverso da temperatura (1/T) para óleo ferroviário comercial, óleo lubrificante ferroviário usado (OLUF) e óleos recuperados por extração com ultrassom

(US) e agitação mecânica (AM) para os solventes isobutanol, 1-butanol e MEK.

A resistência de um lubrificante a variação da viscosidade com a temperatura é indicada pelo Índice de Viscosidade (IV), que é um número arbitrário calculado a partir das viscosidades observadas em duas temperaturas amplamente separadas. Quanto maior o Índice de Viscosidade do óleo, melhor o seu desempenho (CAl et al., 2015; SPEIGHT et al., 2014). A norma padrão ASTM D2270 determina o IV 
conhecendo a viscosidade cinemática do óleo a 40 e a $100^{\circ} \mathrm{C}$

Os óleos básicos minerais são classificados conforme a natureza dos hidrocarbonetos predominantes na sua composição em parafínicos ou naftênicos, o que lhes confere diferentes características e aplicações. De acordo com a aplicação do óleo lubrificante, é necessário atender a diversos requisitos de qualidade, entre eles, a variação da viscosidade com a temperatura. Para esta análise utilizamos um critério empírico denominado Índice de Viscosidade (IV) (ASTM, 2016). Os óleos básicos são classificados nos Grupos I, II, III, IV e naftênicos. Dentre os requisitos do Grupo I e II, o Índice de Viscosidade deve ser maior ou igual a 80 e menor que 120 (ANP, 2017; SPEIGHT et al., 2014). O Índice de Viscosidade é um importante indicador da capacidade de um óleo lubrificar adequadamente nas altas temperatura do motor. Por isso, óleos lubrificantes são formulados com aditivos, geralmente polímeros, melhoradores do Índice de Viscosidade, que podem atingir um índice de até 150 (SPEIGHT et al., 2014).

Os resultados de Índice de Viscosidade para o óleo ferroviário comercial novo foi de 93, corroborando com os valores modais da produção. Para avaliar a qualidade dos óleos recuperados os resultados de IV para isobutanol, 1-butanol e MEK foram de 73, 84 e 88 para US, respectivamente. 0 índice de viscosidade utilizando AM apresentou valores inferiores quando comparados ao US: 68 (isobutanol), 76 (1-butanol) e 82 (MEK). Como pode ser observado, dois óleos recuperados com auxílio de solvente/US podem ser classificados no Grupo I e II de qualidade quanto ao Índice de Viscosidade (84/1-butanol e 88/MEK), enquanto nas mesmas condições, utilizando AM, apenas um dos óleos atingiu os valores exigidos (82/MEK) (SPEIGHT et al., 2014). Estes resultados enfatizam a vantagem do uso do ultrassom para recuperação do óleo. Apesar dos resultados para o solvente MEK atingir a classificação de ambas as condições (US e AM) o uso deste solvente tem desvantagens quanto ao custo que é 1,6 maior que o 1-butanol. Portanto, seria mais indicado o uso de 1butanol e apenas o óleo recuperado usando US atingiu a classificação. A recuperação de óleo lubrificante ferroviário por extração solvente/US produz com óleo próximo dos valores que são usados comercialmente, sugerindo que é uma técnica que pode auxiliar no processo de reciclagem de óleo usado.

\section{CONCLUSÕES}

Concluímos que o parâmetro de solubilidade do óleo lubrificante ferroviário novo aproxima-se de 15,8 $\mathrm{MPa}^{0.5}, 3,8 \mathrm{MPa}^{0.5}$ e 7,6 $\mathrm{MPa}^{0.5}$ para o parâmetro de dispersão, polar e ligação de hidrogênio, respectivamente. $\mathrm{O}$ parâmetro de solubilidade de Hansen identificou os solventes 1-butanol e MEK para o processo de extração. Na mistura de solventes, com o parâmetro de solubilidade foi possível predizer a mistura $70 \% \mathrm{~m} / \mathrm{m}$ de MEK com $30 \% \mathrm{~m} / \mathrm{m}$ de isobutanol como solvente composto que proporcionaria os melhores rendimentos. Esses dados foram corroborados pelo planejamento da mistura de solventes utilizando os solventes isobutanol, 1-butanol e MEK. Os rendimentos de recuperação de óleo usando US foram de $64,0 \% \mathrm{~m} / \mathrm{m}$ (isobutanol), $89,1 \% \mathrm{~m} / \mathrm{m}$ (1-butanol) e $91,2 \% \mathrm{~m} / \mathrm{m}$ (MEK). Os rendimentos para agitação mecânica nas mesmas condições foram inferiores ao encontrados em US: 56,3\% m/m, 83,4\% m/m e $89,1 \% \mathrm{~m} / \mathrm{m}$ para os solventes isobutanol, 1-butanol e MEK, respectivamente. Avaliando a qualidade dos óleos recuperados, o índice de viscosidade para os solventes isobutanol, 1-butanol e MEK, os resultados 
foram de 73, 84 e 88 para US e de 68, 76 e 82 para AM, respectivamente. Considerando que os óleos lubrificantes devem apresentar índice de viscosidade acima de 80, a extração foi mais eficiente utilizando US. Concluímos que o uso de ultrassom é promissor para auxiliar no processo de rerrefino de óleo lubrificante ferroviário usado.

AGRADECIMENTOS: O presente trabalho foi realizado com apoio da Coordenação de Aperfeiçoamento de Pessoal de Nível Superior - Brasil (CAPES) - Código de Financiamento 001. Os autores agradecem ao Conselho Nacional de Desenvolvimento Científico e Tecnológico (CNPq 313272/2019-0 /DT) pelo apoio. Os autores agradecem a VALE por doar as amostras de óleo lubrificante ferroviário usado.

\section{REFERÊNCIAS}

ABBOTT, S.; HANSEN, C. M.; YAMAMOTO, H.. Hansen Solubility Parameters in Practice. 5 ed. Hansen-Solubility, 2015.

ABDULLAH, H. B.; IRMAWATI, R.; ISMAIL, I.; YUSOF, N. A. Utilization of waste engine oil for carbon nanotube aerogel production using floating catalyst chemical vapor deposition Journal of Cleaner Production, v.261, p.121188, 2020. DOI: http://doi.org/10.1016/j.jclepro.2020.121188

ABNT. Associação Brasileira de Normas Técnicas. ABNT NBR 10004: Resíduos sólidos - Classificação. Rio de Janeiro: ABNT, 2004.

ALAVI, S. E.; ABDOLI, M. A.; KHORASHEH, F.; MOGHADDAM, A. B.. Non-isothermal pyrolysis of used lubricating oil and the catalytic effect of carbon-based nanomaterials on the process performance. Journal of Thermal Analysis and Calorimetry, v.139, n.2, p.1025-1036, 2020. DOI: http://doi.org/10.1007/s10973-019-08436-w

ALBERO, B.; TADEO, J. L.; PÉREZ, R. A.. Ultrasound-assisted extraction of organic contaminants. TrAC Trends in Analytical Chemistry, v.118, p.739-750, 2019. DOI: http://doi.org/10.1016/i.trac.2019.07.007

ANP. Resolução ANP n. 669/2017: Especificações dos óleos básicos e suas regras de comercialização. Brasília: ANP, 2017.

ASSUNÇÃO FILHO, J. L.; MOURA, L. G. M.; RAMOS, A. C. S.. Liquid-liquid extraction and adsorption on solid surfaces applied to used lubricant oils recovery. Brazilian Journal of Chemical Engineering, v.27, n.04, p.687-697, 2010. DOI: http://doi.org/10.1590/S0104-66322010000400020

ASTM. D2270-10 (2016) Standard Practice for Calculating Viscosity Index from Kinematic Viscosity at $40{ }^{\circ} \mathrm{C}$ and 100 ${ }^{\circ} \mathrm{C}$. West Conshohocken: ASTM International, 2016. DOI: http://doi.org/10.1520/D2270-10R16

ASTM. D4052-18a Standard Test Method for Density, Relative Density, and API Gravity of Liquids by Digital Density Meter. West Conshohocken: ASTM International, 2018. DOI: http://doi.org/10.1520/D4052-18A

AYLOTT, R. I.; CLYNE, A. H.; FOX, A. P.; WALKER, D. A..
Analytical strategies to confirm Scotch whisky authenticity. Analyst, v.119, n.8, p.1741-1746, 1994. DOI: http://doi.org/10.1039/AN9941901741

BOTAS, J. A.; MORENO, J.; ESPADA, J. J.; SERRANO, D. P.; DUFOUR, J.. Recycling of used lubricating oil: Evaluation of environmental and energy performance by LCA. Resources, Conservation and Recycling, v.125, p.315-323, 2017. DOI: http://doi.org/10.1016/j.resconrec.2017.07.010

BURDOCK, G. A.. Fenaroli's handbook of flavor ingredients. 6 ed. CRC Press, 2010

CAI, G.; ZHANG, L.; MA, L.; ELI, W.. Synthesis and characterization of polybutylacrylate viscosity index improver with anti-wear function. Lubrication Science, v.27, n.4, p.209-216, 1 2015. DOI: http://doi.org/10.1002/ls.1268

CASTRO, M. D. L.; PRIEGO-CAPOTE, F.. Ultrasound assistance to liquid-liquid extraction: a debatable analytical tool. Analytica Chimica Acta, v.583, n.1, p.2-9, 2007. Dol: http://doi.org/10.1016/j.aca.2006.09.039

CHEMAT, F.; ABERT VIAN, M.; FABIANO-TIXIER, A.-S.; NUTRIZIO, M.; REŽEK JAMBRAK, A.; MUNEKATA, P. E. S.; LORENZO, J. M.; BARBA, F. J.; BINELLO, A.; CRAVOTTO, G.. A review of sustainable and intensified techniques for extraction of food and natural products. Green Chemistry, v.22, n.8, p.2325-2353, 2020. DOI: http://doi.org/10.1039/C9GC03878G

CHEMAT, F.; ROMBAUT, N.; SICAIRE, A.-G.; MEULLEMIESTRE, A.; FABIANO-TIXIER, A.-S.; ABERT-VIAN, M.. Ultrasound assisted extraction of food and natural products. Mechanisms, techniques, combinations, protocols and applications. A review. Ultrasonics Sonochemistry, v.34, p.540-560, 2017. DOI: http://doi.org/10.1016/j.ultsonch.2016.06.035

CONAMA. Resolução n. 362: Recolhimento, coleta e destinação final de óleo lubrificante usado ou contaminado. Brasília: CONAMA, 2005.

DAHAM, G. R.; ABDULRAZAK, A. A.; HAMADI, A. S.; MOHAMMED, A. A.. Re-refining of used lubricant oil by solvent extraction using central composite design method. Korean Journal of Chemical Engineering, v.34, n.9, p.2435- 
2444, 2017. DOI: http://doi.org/10.1007/s11814-017-0139-5

ECHA. Guidance on Information Requirements and Chemical Safety Assessment. Chapter R.11: PBT/vPvB Assessment. Helsinki, 2017. Dol:

http://doi.org/10.2823/128621

ELBASHIR, N. O.; AL-ZAHRANI, S. M.; MUTALIB, M. I. A.; ABASAEED, A. E.. A method of predicting effective solvent extraction parameters for recycling of used lubricating oils. Chemical Engineering and Processing: Process Intensification, v.41, n.9, p.765-769, 2002. DOI: http://doi.org/10.1016/S0255-2701(02)00006-5

GOEL, A.; RATHI, S.; AGRAWAL, M.. Toxicity potential of particles caused by particle-bound polycyclic aromatic hydrocarbons (PPAHs) at two roadside locations and relationship with traffic. Environmental Science and Pollution Research, v.25, n.30, p.30633-30646, 2018. DOI: http://doi.org/10.1007/s11356-018-3043-6

GRICE, L. N.; NOBEL, C. E.; LONGSHORE, L.; HUNTLEY, R.; DEVIERNO, A. L.. Life cycle carbon footprint of re-refined versus base oil that is not re-refined. ACS Sustainable Chemistry \& Engineering, v.2, n.2, p.158-164, 2014. DOI: http://doi.org/10.1021/sc400182k

HAMAD, A.; AL-ZUBAIDY, E.; FAYED, M. E.. Used lubricating oil recycling using hydrocarbon solvents. Journal of Environmental Management, v.74, n.2, p.153-159, 2005. DOI: http://doi.org/10.1016/j.jenvman.2004.09.002

HANSEN, C. M.. Hansen Solubility Parameters: a User's Handbook. 2 ed. 2007.

HASHIMOTO, T.; TAKAHASHI, A.; URUSHISAKI, M.; SAKAGUCHI, T.. Synthesis of poly(vinyl ether) polyols with pendant oxyethylene chains and properties of hydrophilic, thermo-responsive polyurethanes prepared therefrom. Journal of Polymer Science Part A: Polymer Chemistry, v.48, n.7, p.1641-1648, 2010. DOI:

http://doi.org/10.1002/pola.23930

HASSANAIN, E. M.; YACOUT, D. M. M.; METWALLY, M. A.; HASSOUNA, M. S.. Life cycle assessment of waste strategies for used lubricating oil. The International Journal of Life Cycle Assessment, v.22, n.8, p.1232-1240, 2017. DOI: http://doi.org/10.1007/s11367-016-1255-x

HOLKAR, C. R.; JADHAV, A. J.; PINJARI, D. V.; PANDIT, A. B.. Cavitationally Driven Transformations: a Technique of Process Intensification. Industrial \& Engineering Chemistry Research, v.58, n.15, p.5797-5819, 2019. Dol: http://doi.org/10.1021/acs.iecr.8b04524

JAFARI, A. J.; HASSANPOUR, M.. Analysis and comparison of used lubricants, regenerative technologies in the world. Resources, Conservation and Recycling, v.103, p.179-191, 2015. DOI: http://doi.org/10.1016/j.resconrec.2015.07.026

JORDAN, A.; STOY, P.; SNEDDON, H. F.. Chlorinated Solvents: Their Advantages, Disadvantages, and Alternatives in Organic and Medicinal Chemistry. Chemical Reviews, v.121, n.3, p.1582-1622, 2020. DOI:

http://doi.org/10.1021/acs.chemrev.0c00709

KAMAL, A.; KHAN, F.. Effect of Extraction and Adsorption on
Re-refining of Used Lubricating Oil. Oil and Gas Science and Technology, v.64, n.2, p.191-197, 2009. Dol: http://doi.org/10.2516/ogst/2008048

KATO, Y.; OSAWA, T.; YOSHIHARA, M.; FUJII, H.; TSUTSUMI, S.; YAMAMOTO, H.. Evaluation of the Antifoaming Effect Using Hansen Solubility Parameters. ACS Omega, v.5, n.11, p.5684-5690, 2020. DOI:

http://doi.org/10.1021/acsomega.9b03567

KHAN, S. A.; DAR, A. H.; BHAT, S. A.; FAYAZ, J.; MAKROO, H. A.; DWIVEDI, M.. High Intensity Ultrasound Processing in Liquid Foods. Food Reviews International, p.1-26, 2020. DOI: http://doi.org/10.1080/87559129.2020.1768404

KULKARNI, V. M.; RATHOD, V. K.. Mapping of an ultrasonic bath for ultrasound assisted extraction of mangiferin from Mangifera indica leaves. Ultrasonics Sonochemistry, v.21, n.2, p.606-611, 2014. DOI:

http://doi.org/10.1016/j.ultsonch.2013.08.021

LEVIN, M.; REDELIUS, P.. Determination of Three-

Dimensional Solubility Parameters and Solubility Spheres for Naphthenic Mineral Oils. Energy \& Fuels, v.22, n.5, p.33953401, 2008. DOI: http://doi.org/10.1021/ef800256u

LEWIS, R. A.; LARRAÑAGA, M. D.; SR, R. J. L.. Hawley's condensed chemical dictionary. 16 ed. Hoboken: John Wiley \& Sons, 2016.

LIU, J.; GU, K.; WANG, D.; ZHAO, Y.. Evaluation of Lubrication Properties of Refortified Hydraulic Oils. Tribology Transactions, v.57, n.3, p.373-381, 2014. DOI: http://doi.org/10.1080/10402004.2013.868565

MCKEE, R. H.; ADENUGA, M. D.; CARRILLO, J.-C..

Characterization of the toxicological hazards of hydrocarbon solvents. Critical Reviews in Toxicology, v.45, n.4, p.273365, 2015. DOI: http://doi.org/10.3109/10408444.2015.1016216

MEDEIROS, F. K.; AQUINOA, R. C. A.; RODRIGUESB, A. M. T.; SILVAB, H. C.; DIASC, I. B. C.; FERREIRAD, H. S.. Produção de tijolos maciços e placas cerâmicas de revestimento com adição de óleo lubrificante usado. Cerâmica Industrial, v.19, n.2, p.38-45, 2014. DOI:

http://doi.org/10.4322/cerind.2014.071

MUSARURWA, H.; TAVENGWA, N. T.. Emerging green solvents and their applications during pesticide analysis in food and environmental samples. Talanta, v.223, p.121507, 2020. DOI: http://doi.org/10.1016/j.talanta.2020.121507

OSMAN, D. I.; ATTIA, S. K.; TAMAN, A. R.. Recycling of used engine oil by different solvent. Egyptian Journal of Petroleum, v.27, n.2, p.221-225, 2018. DOI: http://doi.org/10.1016/i.ejpe.2017.05.010

PENA-PEREIRA, F.; WOJNOWSKI, W.; TOBISZEWSKI, M.. AGREE: Analytical GREEnness Metric Approach and Software. Analytical Chemistry, v.92, n.14, p.10076-10082, 2020. DOI: http://doi.org/10.1021/acs.analchem.0c01887

PINHEIRO, C. T.; PAIS, R. F.; FERREIRA, A. G. M.; QUINA, M. J.; GANDO-FERREIRA, L. M.. Measurement and correlation of thermophysical properties of waste lubricant oil. Journal of Chemical Thermodynamics, v.116, p.137-146, 2018. DOI: 
http://doi.org/10.1016/j.jct.2017.08.039

PINHEIRO, C. T.; QUINA, M. J.; GANDO-FERREIRA, L. M.. New Methodology of Solvent Selection for the Regeneration of Waste Lubricant Oil Using Greenness Criteria. ACS Sustainable Chemistry and Engineering, v.6, n.5, p.68206828, 2018. DOI:

http://doi.org/10.1021/acssuschemeng.8b00646

PINHEIRO, C. T.; PAIS, R. F.; QUINA, M. J.; GANDO-FERREIRA, L. M.. Regeneration of waste lubricant oil with distinct properties by extraction-flocculation using green solvents. Journal of Cleaner Production, v.200, p.578-587, 2018. DOI: http://doi.org/10.1016/j.jclepro.2018.07.282

PINHEIRO, C. T.; QUINA, M. J.; GANDO-FERREIRA, L. M.. Management of waste lubricant oil in Europe: A circular economy approach. Critical Reviews in Environmental Science and Technology, v.51, n.18, p.1-36, 2020. DOI: http://doi.org/10.1080/10643389.2020.1771887

PŁOTKA-WASYLKA, J.. A new tool for the evaluation of the analytical procedure: Green Analytical Procedure Index. Talanta, v.181, p.204-209, 2018. DOI: http://doi.org/10.1016/j.talanta.2018.01.013

QURASHI, I. A.; SWAMY, A. K.. Viscoelastic properties of recycled asphalt binder containing waste engine oil. Journal of Cleaner Production, v.182, p.992-1000, 2018. DOI: http://doi.org/10.1016/i.jclepro.2018.01.237

REIS, M. A.; JERONIMO, M. S.. Waste lubricating oil rerefining by extraction-flocculation. 1 . A scientific basis to design efficient solvents. Industrial \& Engineering Chemistry Research, v.27, n.7, p.1222-1228, 1988. DOI: http://doi.org/10.1021/ie00079a023

REIS, M. A.; JERONIMO, M. S.. Waste lubricating oil rerefining by extraction-flocculation. 2 . a method to formulate efficient composite solvents. Industrial \& Engineering Chemistry Research, v.29, n.3, p.432-436, 1990. DOI: http://doi.org/10.1021/ie00099a019

RINCÓN, J.; CAÑIZARES, P.; GARCÍA, M. T.. Regeneration of Used Lubricant Oil by Polar Solvent Extraction. Industrial \& Engineering Chemistry Research, v.44, n.12, p.4373-4379, 2005. DOI: http://doi.org/10.1021/ie040254j

RINCON, J.; CANIZARES, P.; GARCIA, M. T.. Waste oil recycling using mixtures of polar solvents. Industrial \& Engineering Chemistry Research, v.44, n.20, p.7854-7859, 2005. DOI: http://doi.org/10.1021/ie0580452

SÁNCHEZ-CAMARGO, A. D. P.; BUENO, M.; PARADAALFONSO, F.; CIFUENTES, A.; IBÁÑEZ, E.. Hansen solubility parameters for selection of green extraction solvents. TrAC Trends in Analytical Chemistry, v.118, p.227-237, 2019. DOI: http://doi.org/10.1016/j.trac.2019.05.046

SATHISKUMAR, C.; KARTHIKEYAN, S.. Recycling of waste tires and its energy storage application of by-products-a review. Sustainable Materials and Technologies, v.22, p.e00125, 2019. DOI: http://doi.org/10.1016/j.susmat.2019.e00125

SOUZA, F. O.. Desenvolvimento de método de extraçãofloculação por aplicação de ondas ultrassônicas em óleo lubrificante usado. Dissertação (Mestrado em Energia) -
Universidade Federal do Espírito Santo, São Mateus, 2015.

SPEIGHT, J. G.. The chemistry and technology of petroleum. Boca Raton: CRC press, 2014

SPEIGHT, J.; EXALL, D. I.. Refining used lubricating oils. Boca Raton: CRC press, 2014

SUGIHARA, S.; IWATA, K.; MIURA, S.; MA'RADZI, A. H.; MAEDA, Y.. Synthesis of dual thermoresponsive ABA triblock copolymers by both living cationic vinyl polymerization and RAFT polymerization using a dicarboxylic RAFT agent.

Polymer, v.54, n.3, p.1043-1052, 2013. DOI:

http://doi.org/10.1016/j.polymer.2012.12.039

TAHA, A.; AHMED, E.; ISMAIEL, A.; ASHOKKUMAR, M.; XU, X.; PAN, S.; HU, H.. Ultrasonic emulsification: An overview on the preparation of different emulsifiers-stabilized emulsions. Trends in Food Science \& Technology, v.105, p.363-377, 2020. DOI: http://doi.org/10.1016/j.tifs.2020.09.024

TOROPOV, A. A.; TOROPOVA, A. P.; CAPPELLI, C. I.; BENFENATI, E.. CORAL: Model for octanol/water partition coefficient. Fluid Phase Equilibria, v.397, p.44-49, 2015. DOI: http://doi.org/10.1016/j.fluid.2015.03.051

TSAI, W.-T.. An analysis of used lubricant recycling, energy utilization and its environmental benefit in Taiwan. Energy, v.36, n.7, p.4333-4339, 2011. DOI: http://doi.org/10.1016/i.energy.2011.04.008

VELASCO-CALDERÓN, J. C.; GARCIA-FIGUEROA, A. A.; CERVANTES, J. L. L.; GRACIA-FADRIQUE, J.. Regeneration of used lubricating oil by solvent extraction and phase diagram analysis. Current Research in Green and Sustainable Chemistry, v.3, p.100010, 2020. DOI: http://doi.org/10.1016/j.crgsc.2020.06.003

VOELKEL, A.; FALL, J.. Solubility parameter as polarity measure for high-boiling oil products. Fuel, v.122, p.310-315, 2014. DOI: http://doi.org/10.1016/i.fuel.2014.01.021

WENG, M.. Determination of the Hansen solubility parameters with a novel optimization method. Journal of Applied Polymer Science, v.133, n.16, 2016. DOI: http://doi.org/10.1002/app.43328

WIDODO, S.; ARIONO, D.; KHOIRUDDIN, K.; HAKIM, A. N.; WENTEN, I. G.. Recent advances in waste lube oils processing technologies. Environmental Progress \& Sustainable Energy, v.37, n.6, p.1867-1881, 2018. DOI: http://doi.org/10.1002/ep.13011

WILEY-VCH. Ullmann's Encyclopedia of Industrial Chemistry. 7 ed. Wiley-VCH, 2011.

YANG, X.; CHEN, L.; XIANG, S.; LI, L.; XIA, D.. Regeneration of waste lubricant oil by extraction-flocculation composite refining. Industrial \& Engineering Chemistry Research, v.52, n.36, p.12763-12770, 2013. DOI:

http://doi.org/10.1021/ie4015099

YARA-VARON, E.; FABIANO-TIXIER, A.-S.; BALCELLS, M.; CANELA-GARAYOA, R.; BILY, A.; CHEMAT, F.. Is it possible to substitute hexane with green solvents for extraction of carotenoids? A theoretical versus experimental solubility study. RSC Advances, v.6, n.33, p.27750-27759, 2016. DOI: 
http://doi.org/10.1039/C6RA03016E

ZENG, X.-L.; WANG, H.-J.; WANG, Y.. QSPR models of noctanol/water partition coefficients and aqueous solubility of halogenated methyl-phenyl ethers by DFT method. Chemosphere, v.86, n.6, p.619-625, 2012. DOI: http://doi.org/10.1016/j.chemosphere.2011.10.051
ZGHEIB, N.; TAKACHE, H.. Recycling of used lubricating oil by solvent extraction: experimental results, Aspen Plus simulation and feasibility study. Clean Technologies and Environmental Policy, v.23, p.1-12, 2020. DOI:

http://doi.org/10.1007/s10098-020-01893-0

A CBPC - Companhia Brasileira de Produção Científica (CNPJ: 11.221.422/0001-03) detém os direitos materiais desta publicação. Os direitos referem-se à publicação do trabalho em qualquer parte do mundo, incluindo os direitos às renovações, expansões e disseminações da contribuição, bem como outros direitos subsidiários. Todos os trabalhos publicados eletronicamente poderão posteriormente ser publicados em coletâneas impressas sob coordenação da Sustenere Publishing, da Companhia Brasileira de Produção Científica e seus parceiros autorizados. Os (as) autores (as) preservam os direitos autorais, mas não têm permissão para a publicação da contribuição em outro meio, impresso ou digital, em português ou em tradução. 